\title{
BOLSA FAMÍLIA OU DESEMPENHO DA ECONOMIA? DETERMINANTES DA REELEIÇÃO DE LULA EM 2006
}

\author{
Mauricio Canêdo-Pinheiro *
}

\begin{abstract}
Resumo
Este artigo investiga os determinantes dos resultados das eleições presidenciais brasileiras de 2006, em particular o papel do programa Bolsa Família e do desempenho econômico na migração da base eleitoral de Lula para regiões menos desenvolvidas. Os resultados indicam que, entre eleitores habituais de Lula, a participação no programa não aumenta a probabilidade de voto nesse candidato em 2006. Entre eleitores habituais de outros candidatos, esse efeito é positivo. Além disso, um maior crescimento econômico somente significou votos adicionais para Lula entre os eleitores mais ricos. Por fim, o impacto do programa Bolsa Família se mostrou bastante superior ao do desempenho econômico. No entanto, nenhum dos dois fatores foi capaz de explicar satisfatoriamente toda a extensão da mudança observada em 2006.
\end{abstract}

Palavras-chave: Bolsa Família; Lula; Eleições Presidenciais; Viés de Agregação.

\begin{abstract}
This paper investigates the determinants of the outcome of Brazilian presidential elections in 2006, in particular the role of the Bolsa Família Program and the economic performance in the migration of the electoral base of Lula for less developed regions. Among the usual Lula's electorate, joining the Bolsa Família program did not increase the likelihood of voting in this candidate. Among the other voters, this effect was positive. Moreover, higher economic growth only resulted in more votes for Lula among the richest voters. Regarding the elections results, the impact of Bolsa Família proved to be quite superior than the economic performance. However, neither of the two factors was able to satisfactorily explain the full extent of the observed change in 2006.
\end{abstract}

Keywords: Bolsa Família; Lula; Presidential Elections; Aggregation Bias JEL classification: H53, I38.

DOI: http://dx.doi .org/10.1590/1413-8050/ea 100264

\footnotetext{
* BRE/FGV e FCE/UERJ. E-mail: mauricio.pinheiro@fgv.br
} 


\section{Introdução}

Embora tenha vencido as eleições presidenciais de 2002 e 2006 com praticamente a mesma votação percentual, ficou clara a mudança no perfil da votação do candidato reeleito, Luiz Inácio Lula da Silva (Lula). A Figura 1 ilustra essa afirmação. Cada ponto representa um município brasileiro. A princípio, seria esperada alguma relação positiva entre as votações obtidas por Lula entre duas eleições consecutivas, como ocorreu entre 1998 e 2002. Entretanto, nota-se que praticamente não há relação entre os percentuais de votos obtidos por Lula no primeiro turno, quando comparadas as eleições de 2002 e $2006{ }^{1}$ Se tradicionalmente Lula era bem sucedido em regiões mais desenvolvidas do Brasil, em 2006 o candidato do Partido dos Trabalhadores (PT) viu sua base eleitoral migrar para regiões de menor desenvolvimento. Essa mudança teve uma contrapartida do ponto de vista geográfico (ver Figura 2). Lula melhorou seu desempenho na vasta maioria dos municípios das regiões Norte e Nordeste (são os pontos localizados acima da reta de $45^{\circ}$ ). Nas demais regiões a tendência de melhora e piora foi mais equilibrada.
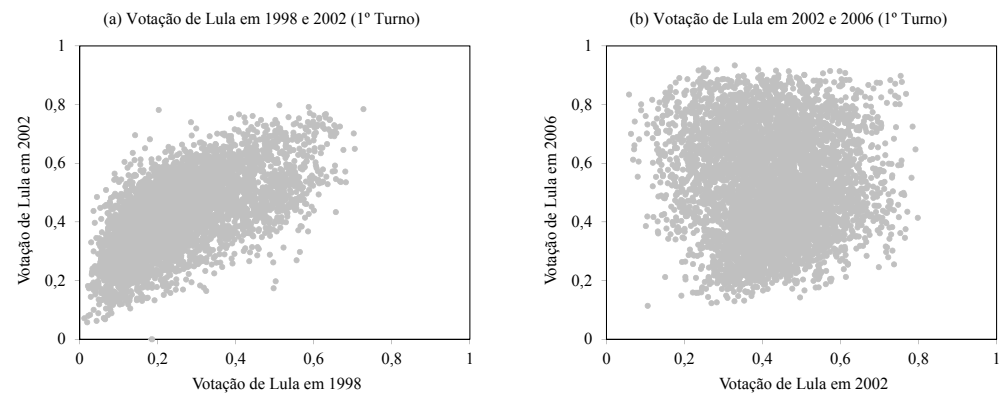

Fonte: Tribunal Superior Eleitoral

Figura 1: Votação de Lula em Diferentes Eleições (\% dos votos válidos no $1^{\circ}$ Turno)
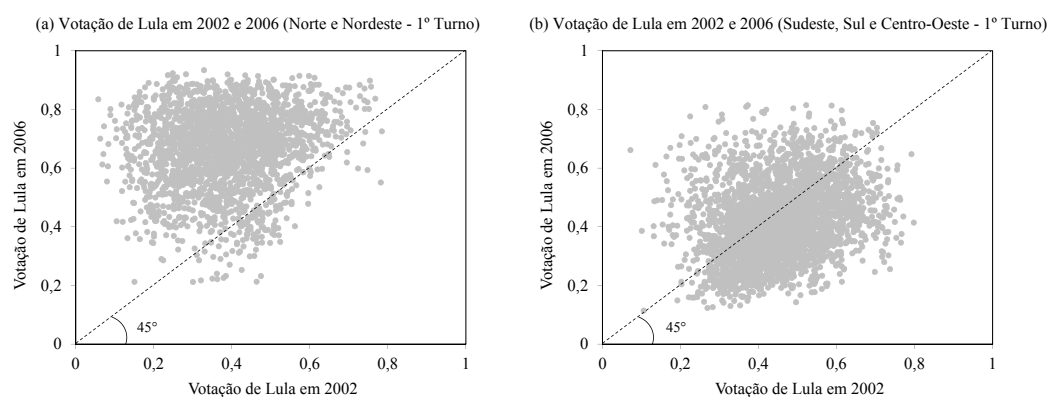

Fonte: Tribunal Superior Eleitoral

Figura 2: Votação de Lula em 2002 e 2006 (\% dos votos válidos no $1^{\circ}$ Turno)

\footnotetext{
${ }^{1}$ Esse último resultado vale também para a votação no segundo turno. Obviamente, não é possível comparar as votações de Lula no segundo turno em 1998 e 2002, pois em 1998 a eleição foi decidida no primeiro turno.
} 
Muitas hipóteses foram levantadas para explicar tal mudança. Em Hunter \& Power (2007) elas foram organizadas em três grandes categorias (não excludentes). Em primeiro lugar, os eleitores mais pobres e menos escolarizados teriam menos acesso à informação sobre os escândalos de corrupção que surgiram no primeiro mandato de Lula. Em segundo lugar, os eleitores de menor renda seriam os mais beneficiados com a política econômica do primeiro governo de Lula. Por último, as políticas sociais, particularmente o programa Bolsa Família, explicariam grande parte do desempenho eleitoral de Lula nas regiões menos desenvolvidas. Além disso, Zucco (2008) aponta evidências de que no Brasil o candidato a presidente ligado ao governo sempre obtém desempenho eleitoral relativamente melhor em regiões menos desenvolvidas, naturalmente mais dependentes do governo. Tal regularidade também ajudaria a explicar o desempenho de Lula nessas regiões.

Sobre a relação entre os programas de transferência de renda e o desempenho de Lula nas eleições de 2006, existe um amplo debate público sobre os dividendos eleitorais do programa Bolsa Família. ${ }^{2}$ Esse debate foi transplantado para o ambiente acadêmico. Os resultados são bastante díspares: variando desde evidências de que o programa não foi determinante para a reeleição de Lula (Shikida et al. 2009) até conclusões de que o programa teve papel decisivo na vitória do candidato do PT (Marques et al. 2009). A propósito, essa literatura não é restrita ao caso brasileiro: há artigos que investigam o impacto de programas de transferência de renda nos resultados de eleições em outros países (ver Labonne (2013) e De La O (2013), por exemplo).

A respeito do papel do desempenho da economia brasileira na mudança do padrão eleitoral de Lula em 2006, muitos autores defendem a prevalência de fatores econômicos. Para eles, os ganhos de bem-estar ligados à melhora das condições do mercado de trabalho para a parcela mais pobre da população e ao impacto do câmbio valorizado e da inflação controlada na cesta de consumo dos estratos de renda mais baixos - e não os ganhos auferidos como os programas de transferência de renda - teriam sido os fatores decisivos nas eleições presidenciais de 2006 (Shikida et al. 2009). Entretanto, apenas artigos mais recentes (ver, por exemplo, Souza \& Cribari Neto (2013)) tentaram inferir diretamente o efeito das variáveis econômicas na reeleição de Lula e contrapôlas ao efeito do programa Bolsa Família. Por exemplo, Shikida et al. (2009) inferem a importância dos fatores econômicos de maneira indireta: como o efeito do programa Bolsa Família mostra-se pequeno, o resultado das eleições é creditado ao desempenho da economia. ${ }^{3}$ Sendo assim, outra contribuição deste artigo é a inclusão de uma medida de desempenho econômico na análise quantitativa do desempenho eleitoral de Lula em 2006, o que possibilita a comparação direta da importância dos fatores econômicos e do programa Bolsa Família.

Em termos metodológicos, a literatura sobre o tema costuma lançar mão de modelos lineares. Esses modelos não são adequados para descrever variáveis que assumem a forma de proporções. Nesse caso, são necessários modelos que se ajustem ao fato de que a variável dependente - proporção de votos em Lula - somente pode assumir valores entre zero e um. Nesse sentido, este trabalho busca suprir essa lacuna ao considerar adequadamente essa questão.

\footnotetext{
${ }^{2}$ Para um resumo deste debate na imprensa ver Marques et al. (2009).

${ }^{3} \mathrm{Na}$ verdade, os próprios autores reconhecem a necessidade de análise quantitativa adicional para identificar e medir adequadamente a importância relativa de cada fator.
} 
No entanto, existe outro problema metodológico, muito mais relevante, ainda não tratado nessa literatura. Por conta do mecanismo de voto secreto, é necessário o uso de dados agregados para investigar o impacto do programa Bolsa Família na votação de Lula em 2006. Tal procedimento é suscetível ao que se convencionou denominar falácia ecológica (King 1997) ou viés de agregação (Stoker 1993). Se os eleitores têm características heterogêneas, não seria possível inferir os padrões de comportamento individual com base em dados agregados. ${ }^{4}$ Desse modo, conclusões tiradas a partir de dados agregados são potencialmente viesadas e podem não refletir o padrão de escolha individual. As exceções seriam situações em que o modelo individual é linear, o que claramente não é o caso quando a variável de decisão do eleitor é discreta (votar ou não votar em Lula, por exemplo). ${ }^{5}$ Trata-se de problema similar à agregação de demandas individuais, tal como descrito no trabalho seminal de Gorman (1953).

Sendo assim, outra contribuição deste artigo - inédita na literatura que estuda os determinantes da reeleição de Lula - é o tratamento adequado dessa questão. Para tanto será utilizado o método de agregação proposto em Kelejian (1995). Esse método, se não permite inferir os parâmetros individuais de escolha, garante que o modelo agregado seja consistente com o modelo individual, evitando o problema de viés de agregação. Além disso, embora a identificação perfeita dos parâmetros individuais não seja possível, conseguese fazer algumas inferências sobre o comportamento individual dos eleitores, mesmo com dados agregados.

Além desta introdução, este artigo conta com mais cinco seções. A seção 2 descreve o modelo de escolha dos eleitores, enquanto a seção 3 mostra como construir um modelo agregado compatível com as decisões individuais. Por sua vez, a seção 4 descreve os dados utilizados e a especificação exata do referido modelo. A seção 5 traz os resultados da estimação do modelo agregado, bem como uma discussão dos mesmos e algumas inferências sobre o processo de decisão individual dos eleitores. Seguem breves considerações finais.

\section{As Escolhas Individuais}

Defina-se a utilidade indireta do $i$-ésimo eleitor, que reside no município $s \leq$ $S$, caso tenha votado em Lula nas eleições presidenciais de 2006:

$$
u_{i s}=\delta+Z_{s}^{\prime} \beta+X_{i s}^{\prime} \gamma+\varepsilon_{i s},
$$

em que $S$ é o total de municípios, $Z_{S}$ é vetor com variáveis que assumem o mesmo valor para todos os eleitores de um mesmo município, $X_{i s}$ é vetor com variáveis específicas dos eleitores, $\delta$ é parâmetro, $\beta$ e $\gamma$ são vetores de parâmetros e $\varepsilon_{i s}$ é o termo de erro aleatório. Por sua vez, a utilidade indireta do eleitor, caso não vote em Lula, é normalizada para zero.

\footnotetext{
${ }^{4}$ Dado o caráter secreto dos votos, este é um problema recorrente na literatura que analisa os resultados de eleições (ver, por exemplo, Brown \& Payne 1986, Freedman et al. 1991, Heckelman 1997, 2000).

${ }^{5}$ Alguns autores tentam contornar esse problema usando dados individuais extraídos de pesquisas de opinião (Bohn 2011, Licio et al. 2009, Zucco 2013). Entretanto, muitas dessas pesquisas sequer conseguem reproduzir o percentual de votação obtido pelos candidatos nas eleições de 2006. Desse modo, não há como escapar do uso de dados agregados.
} 
Caso tivéssemos acesso aos votos de cada eleitor, somente seria possível observar a decisão de cada um (mas não a utilidade indireta). Sendo assim, é conveniente definir $D_{i s}$ tal que:

$$
\begin{aligned}
& D_{i s}=1 \text { se o eleitor escolheu Lula, ou seja, se } u_{i s}=\delta+Z_{s}^{\prime} \beta+X_{i s}^{\prime} \gamma+\varepsilon_{i s} \geq 0 \\
& D_{i s}=0 \text { caso contrário, ou seja, se } u_{i s}=\delta+Z_{s}^{\prime} \beta+X_{i s}^{\prime} \gamma+\varepsilon_{i s}<0
\end{aligned}
$$

Desse modo, se $\varepsilon_{i s}$ é idêntico e independentemente distribuído com densidade simétrica e distribuição acumulada $F\left(Z_{s}, X_{i s}\right)$, a probabilidade de um indivíduo votar em Lula em determinada eleição, ou seja, $E\left(D_{i s} \mid Z_{s}, X_{i s}\right)$, é dada por:

$$
\begin{aligned}
\mu_{i s} \equiv E\left(D_{i s} \mid Z_{s}, X_{i s}\right) & =\operatorname{Pr}\left(D_{i s}=1 \mid Z_{s}, X_{i s}\right) \\
& =\operatorname{Pr}\left(\delta+Z_{s}^{\prime} \beta+X_{i s}^{\prime} \gamma+\varepsilon_{i s} \geq 0\right) \\
& =1-F\left(-\delta-Z_{s}^{\prime} \beta-X_{i s}^{\prime} \gamma\right) \\
& =F\left(\delta+Z_{s}^{\prime} \beta+X_{i s}^{\prime} \gamma\right)
\end{aligned}
$$

Percebe-se que a utilização de modelos lineares se mostra inadequada, pois nesse caso não há como garantir que $0 \leqslant \delta+Z_{s} \beta+X_{i s} \gamma \leqslant 1$, como convém para uma probabilidade. Sob a hipótese de que $\mu_{i s}=F\left(Z_{s}, X_{i s}\right)=\frac{e^{\delta+Z_{s}^{\prime} \beta+X_{i s}^{\prime} \gamma}}{1+e^{\delta+Z_{s}^{\prime} \beta+X_{i s}^{\prime} \gamma}}$ chegase aos modelos da família logit. Desse modo, a escolha dos eleitores que vivem em um determinado município pode ser modelada como (Train 2003):

$$
\ln \left(\frac{\mu_{i s}}{1-\mu_{i s}}\right)=\delta+Z_{s}^{\prime} \beta+X_{i s}^{\prime} \gamma
$$

Os coeficientes de 4 não são diretamente interpretáveis, mas é possível calcular os efeitos marginais de cada variável (Train 2003):

$$
\frac{\partial \mu_{i s}}{\partial W_{i s}}=\mu_{i s}\left(1-\mu_{i s}\right) \vartheta=\frac{e^{\delta+W_{i s}^{\prime} \vartheta}}{\left(1+e^{\delta+W_{i s}^{\prime} \vartheta}\right)^{2}}
$$

em que $\vartheta=\left[\begin{array}{l}\beta \\ \gamma\end{array}\right]$ é vetor de parâmetros e $W_{i s}=\left[\begin{array}{c}Z_{s} \\ X_{i s}\end{array}\right]$ é vetor que variáveis explicativas.

\section{Das Escolhas Individuais Para o Resultado Agregado}

A estimação dos coeficientes da equação 4 requer informações a respeito de cada eleitor. Infelizmente, uma vez que o voto é secreto, as informações individuais não estão disponíveis. Na estimação de modelos lineares de escolha individual, este problema pode ser contornado pela agregação dos atributos e escolhas individuais em diferentes regiões geográficas (municípios, no caso em análise) (Stoker 1993). Os parâmetros do modelo de decisão individual são então estimados pela regressão das médias da variável dependente nas regiões nas mesmas médias dos regressores e em variáveis dummy para as coortes.

Sendo assim, uma questão se impõe: seria possível uma abordagem análoga no caso de modelos da família logit, intrinsecamente não lineares? Para responder a essa questão definam-se: 


$$
\begin{gathered}
\bar{D}_{s}=\frac{\sum_{i=1}^{N_{s}} D_{i s}}{N_{s t}} \\
\bar{X}_{s}=\frac{\sum_{i=1}^{N_{s}} X_{i s}}{N_{s}}
\end{gathered}
$$

em que $N_{s}$ é o número de eleitores da região $s$ na eleição presidencial de 2006. Perceba que as variáveis de caráter individual passam a ser expressas em termos de proporções ou médias relativas à região. Por exemplo, a variável dummy que indica a escolha individual de votar ou não votar em Lula é transformada na proporção de votos desse candidato na região $\left(\bar{D}_{s}\right)$. Se a variável for, por exemplo, renda, passa a ser expressa como renda média dos eleitores da região. Tem-se que de forma geral:

$$
\eta\left(\mu_{s}\right)=\kappa\left(Z_{s}, \bar{X}_{s}\right)
$$

em que $\eta($.$) e \kappa($.$) são funções.$

A especificação 7 levanta três questões. A primeira diz respeito à função $\eta($.): é preciso preservar no modelo agregado a estrutura não linear do modelo de decisão individual descrito em 4 (Stoker 1993) ${ }^{6}$. De outra forma a variável dependente poderá assumir qualquer valor em real quando na verdade é definida no intervalo $[0,1]$. Além disso, modelos lineares resultam em efeitos marginais que independem dos valores das variáveis explicativas. É razoável imaginar que tais efeitos sejam diferentes para valores distintos dessas variáveis. $^{7}$ Desse modo, não é adequado o uso de modelos lineares tal como em Nicolau \& Peixoto (2007), Soares \& Terron (2008), Zucco (2008), Shikida et al. (2009) e Marques et al. (2009). ${ }^{8}$ Nesse caso, a escolha mais óbvia é acompanhar o modelo de decisão individual e usar a função logística, ou seja, $\ln \left(\frac{\mu_{s}}{1-\mu_{s}}\right)$. Aliás, essa escolha é amparada pela constatação de que modelos com função de ligação logística obtêm desempenho bastante superior aos modelos com funções de ligação linear (ver Kieschnick \& McCullough (2003) para evidências e referências).

A segunda questão se refere à função $\kappa($.). Usualmente ela é definida como sendo linear, ou seja, $\kappa\left(Z_{s}, \bar{X}_{s}\right)=\delta+Z_{s}^{\prime} \beta+\bar{X}_{s}^{\prime} \gamma$. No entanto, tal especificação de $\kappa($.) não é adequada se há heterogeneidade dos indivíduos dentro das regiões (Kelejian 1995). Na verdade, essa especificação parte do pressuposto equivocado de que $E\left[\kappa\left(Z_{s}, \bar{X}_{s}\right)\right]=\kappa\left[Z_{s}, E\left(X_{i s}\right)\right]$ dentro de cada região (Heckelman \& Sullivan 2002). Essa igualdade somente vale no caso em que os atributos individuais não variam entre os eleitores da mesma região. Nesse caso, a princípio, a inclusão dos atributos individuais no modelo implica ter que fazer hipóteses mais específicas sobre a distribuição dos mesmos entre os indivíduos. Obviamente, isso tende a complicar a especificação do modelo agregado, pois se

\footnotetext{
${ }^{6}$ A função $\eta$ (.) é usualmente denominada função de ligação (Kieschnick \& McCullough 2003).

${ }^{7}$ Para os valores médios das variáveis explicativas é bastante provável que os efeitos marginais sejam semelhantes para modelos não lineares e lineares, uma vez que estes últimos podem ser considerados aproximações de primeira ordem dos demais. No entanto, quanto mais distante das médias, pior será esta aproximação.

${ }^{8}$ Uma exceção é Souza \& Cribari Neto (2013), que usam a função de ligação logística.
} 
torna necessário incluir a estrutura da distribuição dos atributos individuais como parte do modelo (Stoker 1993). Esse tema será retomado com mais detalhes na seção 3.1.

Por sua vez, a terceira questão diz respeito à heterocedasticidade dos erros e à distribuição condicional de $\bar{D}_{s}$, tema que será tratado em maior profundidade na seção 3.2 .

\subsection{Correta Agregação das Decisões Individuais}

A este respeito, Kelejian (1995) propõe um método que prescinde de qualquer hipótese sobre a distribuição exata dos atributos individuais e, ao mesmo tempo, leva em consideração a heterogeneidade dos mesmos. Esse método é baseado no resultado de que, sob condições bastante gerais, o equivalente agregado do modelo de decisão individual descrito em 4 é: ${ }^{9}$

$$
\ln \left(\frac{\bar{D}_{s}}{1-\bar{D}_{s}}\right)=\delta+Z_{s}^{\prime} \beta+\bar{X}_{s}^{\prime} \gamma+g\left(Z_{s}^{\prime} \beta+\bar{X}_{s}^{\prime} \gamma\right)+v_{s}
$$

em que $g($.$) é uma função que pode ser interpretada como o viés de agregação$ causado pela heterogeneidade dos atributos individuais (Kelejian 1995). Em outras palavras, tem-se que $\kappa\left(Z_{s}^{\prime}, \bar{X}_{s}^{\prime}\right)=\delta+Z_{s}^{\prime} \beta+\bar{X}_{s}^{\prime} \gamma+g\left(Z_{s}^{\prime} \beta+\bar{X}_{s}^{\prime} \gamma\right)$. Tal como sugerido em Stoker (1993), o viés e a forma funcional exata de $g($.$) dependem$ da distribuição de $X_{i s}$ entre os eleitores. No entanto, Kelejian (1995) sugere que $g($.$) é não linear e pode ser aproximada por um polinômio de ordem K$ :

$$
g\left(Z_{s}^{\prime} \beta+\bar{X}_{s}^{\prime} \gamma\right) \approx \sum_{k=0}^{K}\left(Z_{s}^{\prime} \beta+\bar{X}_{s}^{\prime} \gamma\right)^{k} b_{k}
$$

em que $b_{k}$ é o parâmetro associado a k-ésima potência do polinômio.

Defina-se o vetor $\bar{W}_{s}=\left[\begin{array}{c}Z_{s} \\ \bar{X}_{s}\end{array}\right]$. Substituindo-se 9 em 8 e ignorando-se os erros de aproximação, chega-se a (Kelejian 1995):

$$
\begin{aligned}
\underbrace{\ln \left(\frac{\bar{D}_{s}}{1-\bar{D}_{s}}\right)}_{\bar{d}_{s}} & =\delta+\bar{W}_{s}^{\prime} \vartheta+\sum_{k=0}^{K}\left(\bar{W}_{s}^{\prime} \vartheta\right)^{k} b_{k}+v_{s} \\
& =\underbrace{b_{0}+\delta}_{a}+\bar{W}_{s}^{\prime} \underbrace{\vartheta\left(1+b_{1}\right)}_{\lambda}+\sum_{k=2}^{K}\left(\bar{W}_{s}^{\prime} \vartheta\right)^{k} \underbrace{\frac{b_{k}}{\left(1+b_{k}\right)^{k}}}_{\phi_{k}}+v_{s}
\end{aligned}
$$

Desse modo, em vista das hipóteses feitas, a equação 10 representa a agregação apropriada do modelo exposto em 4. Além disso, a equação 10 pode ser usada para se testar a presença de viés de agregação: Kelejian (1995) sugere que nesse caso a hipótese nula seja definida como $\phi_{2}=\ldots=\phi_{k}=0$. Observe que esse teste não é capaz de detectar viés de agregação quando este assume a forma puramente linear.

\footnotetext{
${ }^{9} \mathrm{O}$ resultado não depende, por exemplo, da independência da distribuição dos atributos individuais dentro de cada município.
} 
Revertendo a transformação logística, também é possível calcular (Kelejian 1995):

$$
\operatorname{Pr}\left(D_{i s}=1 \mid \bar{W}_{s}\right) \approx \frac{e^{a+\bar{W}_{s}^{\prime} \lambda+\sum_{k=2}^{K}\left(\bar{W}_{s}^{\prime} \lambda\right)^{k} \phi_{k}}}{1+e^{a+\bar{W}_{s}^{\prime} \lambda+\sum_{k=2}^{K}\left(\bar{W}_{s}^{\prime} \lambda\right)^{k} \phi_{k}}} \equiv \Lambda\left(\bar{W}_{s}^{\prime}, K\right) .
$$

Basicamente 11 representa uma média ponderada da probabilidade individual, na qual os pesos são determinados pelas informações regionais agregadas. Note-se que não se trata da previsão de $\mu_{i s}$, que é a probabilidade condicionada ao vetor $W_{i s}$. Como para cada eleitor a probabilidade de votar em Lula é função das características individuais, a melhor estimativa para uma pessoa escolhida aleatoriamente em determinada região é a média ponderada de todas as possíveis probabilidades heterogêneas naquela mesma região (Heckelman 1997).

Definindo-se $\phi_{1}=1$, não é difícil mostrar que o efeito marginal das variáveis explicativas é:

$$
\frac{\partial \bar{D}_{s}}{\partial \bar{W}_{s}^{\prime}}=\left[\Lambda\left(\bar{W}_{s}, K\right)\right]\left[1-\Lambda\left(\bar{W}_{s}, K\right)\right]\left[\sum_{k=1}^{K}\left(\bar{W}_{s}^{\prime} \lambda\right)^{k-1} k \phi_{k}\right] \lambda
$$

\subsection{Heterocedasticidade dos Erros e Distribuição Condicional de $\bar{D}_{s t}$}

Tomando-se o modelo definido por 10, tem-se que $\sigma_{s} \equiv \operatorname{Var}\left(v_{s}\right)=\frac{1}{N_{s} \mu_{s}\left(1-\mu_{s}\right)}$ (Maddala 1983, p. 29-30). Além disso, tais variâncias podem ser estimadas pela substituição de por sua contrapartida amostral. Sendo assim, o modelo 10 pode ser estimado por Mínimos Quadrados Não Lineares Generalizados (MQNLG), em que cada observação é ponderada por $w_{s}=N_{s} \bar{D}_{s}\left(1-\bar{D}_{s}\right){ }^{10}$

Note-se que a variância de $\bar{D}_{s}$ deve ser heterocedástica e se aproximar de zero nos limites inferior e superior do intervalo [0,1] (Kieschnick \& McCullough 2003). Não é difícil mostrar que essa propriedade é satisfeita pelo modelo $10 .{ }^{11}$

Além disso, embora usualmente o modelo 10 seja estimado pela minimização da soma dos quadrados dos resíduos, implicitamente faz-se a hipótese de que $v \sim N\left(0, \sigma_{s}\right)$ (Kieschnick \& McCullough 2003). Em outras palavras, supõe-se que $\bar{D}_{s}$ tem distribuição normal. ${ }^{12}$ No entanto, essa não é a única possibilidade. Em Kieschnick \& McCullough (2003) são abordadas outras opções, como as distribuições beta e simplex.

\footnotetext{
${ }^{10} \mathrm{Na}$ verdade, os pesos devem ser redefinidos para que sua soma seja igual ao número de observações.

${ }^{11}$ Basta notar que $v \cong \frac{\bar{D}_{s}-u_{s}}{1-u_{s}}$ (Maddala 1983, p. 30). Então $\sigma_{s}=\left[\frac{1}{\mu_{s}\left(1-\mu_{s}\right)}\right]^{2} \operatorname{Var}\left(\bar{D}_{s}\right)$, o que estabelece o resultado de que $\operatorname{Var}\left(\bar{D}_{s}\right)=\frac{\mu_{s}\left(1-\mu_{s}\right)}{N_{s}}$. Note que $\operatorname{Var}\left(\bar{D}_{s}\right)$ se aproxima de zero quando $\mu_{s}$ se aproxima de zero ou um.

${ }^{12}$ Esta hipótese implica assumir que $\bar{D}_{s}$ tem distribuição aditiva logística normal.
} 


\section{Dados e Especificação do Modelo}

\subsection{Dados}

A Tabela 1 traz uma lista e uma breve descrição das variáveis utilizadas. As fontes desses dados são basicamente Zucco (2008) e Tribunal Superior Eleitoral (TSE), para as variáveis eleitorais, o Instituto Brasileiro de Geografia e Estatística (IBGE) para as variáveis geográficas, demográficas e socioeconômicas e Ministério do Desenvolvimento Social (MDS) para informações sobre a cobertura do programa Bolsa Família e do número de famílias pobres.

Por sua vez, a Tabela 2 traz algumas estatísticas descritivas dessas variáveis. Fica bastante evidente a disparidade das características socioeconômicas e demográficas entre os municípios da amostra. A título de exemplo, a menor renda per capita da amostra é de $\mathrm{R} \$ 28,38$ por mês e a maior de $\mathrm{R} \$$ 954,65 , mais do que trinta vezes superior. Os municípios mais desenvolvidos chegam a ter taxas de analfabetismos inferiores a $1 \%$, enquanto os menos desenvolvidos podem ter mais do que $60 \%$ de sua população acima de 15 anos analfabeta.

\subsection{Especificação do Modelo}

Basicamente, foram estimadas diferentes versões do modelo definido em 10, tanto para os votos de Lula no primeiro turno (LULA20061T) quanto para os votos desse candidato no segundo turno (LULA20062T), ambos transformados pela função logística, obviamente. As demais variáveis listadas na Tabela 1 foram usadas como regressores. Adicionalmente, foram incluídas dummies estaduais para capturar o efeito de atributos não observáveis e de variáveis omitidas dentro das unidades federativas. ${ }^{13}$ As variáveis de maior interesse são BOLSA e CRESC, que capturam o alcance do programa Bolsa Família (BOLSA) e o desempenho econômico no primeiro mandato de Lula em termos de crescimento do PIB per capita (CRESC). As demais variáveis explicativas podem ser agrupadas em quatro categorias: (i) geográficas - URB, DENS, DIST; (ii) políticas e eleitorais - LULA20021T (ou LULA20022T), GOVPT, PREFPT e PT2004; (iii) características socioeconômicas dos eleitores - RENDA, GINI, ANALF, MORT, POBRES, PENT, NBRANCO; (iv) setor público - TXLOCAL, PUBLICO.

\section{Resultados}

A Tabela 3 e a Tabela 4 resumem os resultados encontrados a partir da estimação de diferentes versões do modelo descrito na seção 4.2. Em todas as especificações foi utilizado o método de Mínimos Quadrados Não-Lineares Generalizados (MQNLG). Entretanto, esses resultados podem ser mais bem interpretados se expressos em termos de efeitos marginais. Nesse sentido, a Tabela 5 apresenta os efeitos marginais e elasticidades calculados para algumas das especificações.

\footnotetext{
${ }^{13} \mathrm{Na}$ verdade, para evitar multicolinearidade perfeita com outras variáveis, foram omitidas as dummies correspondentes aos estados de Roraima e Acre.
} 
Tabela 1: Variáveis Utilizadas ${ }^{a}$

\begin{tabular}{|c|c|c|}
\hline Variável & Definição & Fonte \\
\hline LULA20061T & \% de votos de Lula sobre votos válidos no $1^{\circ}$ turno da eleição de 2006 & $T S E^{b}$ \\
\hline LULA20062T & \% de votos de Lula sobre votos válidos no $2^{\circ}$ turno da eleição de 2006 & $T S E^{b}$ \\
\hline BOLSA & \% das famílias atendidas pelo programa Bolsa Família em julho de 2006 & $M D S^{b}$ \\
\hline CRESC & Taxa de crescimento anual média do PIB per capita entre 2002 e 2006 (\%) & IBGE \\
\hline URB & \% da população vivendo em áreas urbanas em 2000 & IBGE \\
\hline DENS & Densidade populacional em 2000 (habitantes por $K m^{2}$ ) & IBGE \\
\hline DIST & Distância da capital do estado (Km) & IBGE \\
\hline LULA20021T & \% de votos de Lula sobre votos válidos no $1^{\circ}$ turno da eleição de 2002 & $T S E^{b}$ \\
\hline LULA20022T & \% de votos de Lula sobre votos válidos no $2^{\circ}$ turno da eleição de 2002 & $T S E^{b}$ \\
\hline GOVPT & Variável binária: 1 se governador do PT em 2006, zero caso contrário & Zucco $(2008)$ \\
\hline PREFPT ${ }^{c}$ & Variável binária: 1 se prefeito do PT em 2006, zero caso contrário & Zucco $(2008)$ \\
\hline PT $2004^{c}$ & \% de votos dos candidatos do PT a prefeito nas eleições municipais de 2004 & Zucco $(2008)$ \\
\hline RENDA & Renda per capita mensal em 2000 (R\$ de 2000) & IBGE \\
\hline GINI & Índice de desigualdade de Gini em 2000 & IBGE \\
\hline ANALF & \% de analfabetos entre pessoas acima de 15 anos em 2000 & IBGE \\
\hline MORT & $\%$ de crianças mortas até 5 anos de idade em 2000 & IBGE \\
\hline POBRES & \% de famílias pobres - renda familiar per capita inferior a $\mathrm{R} \$ 100$ & MDS \\
\hline PENT & \% da população de orientação religiosa pentecostal em 2000 & IBGE \\
\hline NBRANCO & \% da população que não declarou ser branca em 2000 & $I B G E^{b}$ \\
\hline TXLOCAL & Impostos locais como proporção da receita operacional em 2006 (\%) & IBGE \\
\hline PUBLICO & Administração Pública como proporção do PIB em 2006 (\%) & IBGE \\
\hline
\end{tabular}


Tabela 2: Algumas Estatísticas Descritivas

\begin{tabular}{lccrr}
\hline Variável & Média & Desvio-Padrão & Mínimo & \multicolumn{1}{c}{ Máximo } \\
\hline LULA20061T & 0,510 & 0,173 & 0,132 & 0,934 \\
LULA20062T & 0,613 & 0,164 & 0,196 & 0,963 \\
BOLSA & 0,289 & 0,166 & 0,013 & 1,000 \\
CRESC & 0,014 & 0,086 & $-0,452$ & 0,763 \\
URB & 0,605 & 0,238 & 0,000 & 1,000 \\
DENS & 123,14 & 625,97 & 0,100 & 12881 \\
DIST & 250,94 & 165,76 & 0,000 & 1474 \\
LULA20021T & 0,437 & 0,119 & 0,058 & 0,798 \\
LULA20022T & 0,548 & 0,123 & 0,125 & 0,906 \\
GOVPT & 0,065 & 0,247 & 0,000 & 1,000 \\
PREFPT & 0,090 & 0,286 & 0,000 & 1,000 \\
RENDA & 180,28 & 100,28 & 28,38 & 954,65 \\
GINI & 0,562 & 0,059 & 0,370 & 0,820 \\
ANALF & 0,207 & 0,124 & 0,009 & 0,607 \\
MORT & 0,042 & 0,029 & 0,006 & 0,135 \\
POBRES & 0,277 & 0,157 & 0,024 & 0,978 \\
PENT & 0,084 & 0,055 & 0,001 & 0,461 \\
NBRANCO & 0,450 & 0,251 & 0,003 & 0,987 \\
TXLOCAL & 0,053 & 0,053 & 0,001 & 0,510 \\
PUBLICO & 0,260 & 0,140 & 0,010 & 0,785 \\
\hline
\end{tabular}

Estatísticas calculadas para uma amostra de 3.398 municípios e não ponderadas pela população. Foram eliminadas as observações em que não estava disponível informação para alguma variável.

\subsection{Viés de Agregação}

Pela inspeção da Tabela 3 e da Tabela 4 percebe-se que o viés de agregação é detectado em todos os modelos (com exceção dos Modelos A1 e B1, obviamente): a hipótese nula de que $\phi_{2}=0$ (Modelos A2 e B2) ou $\phi_{2}=\phi_{3}=0$ (Modelos A3 e B3) foi fortemente rejeitada. ${ }^{14}$

Note-se que as evidências de Heckelman \& Sullivan (2002) mostram que: (i) a presença de viés de agregação aumenta com a população das regiões; (ii) a capacidade do teste proposto por Kelejian (1995) em detectar esse viés também aumenta com o tamanho da população. Nesse sentido, a constatação de que o viés de agregação é importante mesmo com dados municipais lança muitas dúvidas sobre evidências baseadas em dados agregados estaduais, sujeitos a um viés ainda maior. Outro resultado dos mesmos autores indica que o poder desse teste aumenta sensivelmente com a ordem do polinômio $(K)$ utilizado na aproximação da função $g($.$) e pode ser bastante baixo para valores$ pequenos de $K$. O fato de que a detecção foi conseguida mesmo para $K=2$ reforça as evidências de que o viés de agregação não pode ser desprezado. Tanto é verdade, que os efeitos marginais e as elasticidades calculadas para modelos com $\mathrm{K}=3$ diferem substancialmente dos calculados para modelos com $K=1$ (ver mais detalhes no apêndice ao final do artigo).

Também foram estimadas versões do modelo para $K>3$. No entanto, optou-se por apresentar somente os resultados para $K \leq 3$, pois as estimati-

\footnotetext{
${ }^{14}$ Os modelos indexados pela letra $A$ se referem aos votos do $1^{\circ}$ turno, os indexados pela letra $B$ dizem respeito ao $2^{\circ}$ turno.
} 
vas são bastante similares. Além disso, para $K>3$, o $R^{2}$ ajustado e o critério de informação de Akaike indicam que os ganhos em termos de ajuste não compensam as perdas de graus de liberdade. ${ }^{15}$ Sendo assim, os Modelos A3 e B3 foram selecionados como preferidos.

\subsection{Interpretação dos Resultados: Primeiras Impressões}

Primeiramente, ressalte-se que os resultados para o primeiro e segundo turnos são semelhantes. Para a maioria das variáveis observou-se o mesmo sinal e efeitos marginais (ou elasticidades) similares nos dois casos. Uma diferença importante é o ganho relativo de relevância da variável CRESC no segundo turno (o efeito marginal quase dobrou). Esse aspecto será explorado mais adiante.

Da Tabela 5 percebe-se também que, tomadas individualmente, as variáveis $L U L A 20021 T$ e LULA20022T possuem o maior impacto na votação de Lula nas eleições presidenciais de 2006. Um aumento de um ponto percentual na votação de Lula em 2002 significa incremento de $0,4501(0,5452)$ ponto percentual nos votos desse candidato no primeiro turno (segundo turno) em 2006. Nesse sentido, embora haja indicação de que o padrão de votos de Lula mudou entre 2002 e 2006, a votação do mesmo ainda se mostrou bastante influenciada pelo seu desempenho eleitoral passado.

O sinal das variáveis sociodemográficas relativas às minorias também foi o esperado. Tudo mais constante, a votação de Lula foi superior em municípios com maior participação de negros, pardos e índios na população (NBRANCO), o que seria de se esperar dado o apelo de seu primeiro governo no que tange às desigualdades raciais Zucco (2008). Um aumento de $1 \%$ nessa variável gera incremento de $0,2520 \%(0,1946 \%)$ na votação de Lula no primeiro turno (segundo turno) em 2006 (ver Tabela 5). O mesmo com relação aos evangélicos ligados às igrejas pentecostais (PENT), embora com uma elasticidade inferior. ${ }^{16}$

Das variáveis políticas, a presença de governador do PT (GOVPT) e a votação dos candidatos do PT nas eleições municipais de 2004 (PT 2004) aparecem com o sinal esperado. No entanto, a presença de prefeito do PT apresentou sinal negativo, contrário do esperado. Trata-se do mesmo resultado encontrado em Zucco (2008). Mas, provavelmente, o sinal dessa variável não indica que os prefeitos do PT atrapalharam o desempenho eleitoral de Lula em seus municípios. A variável pode ser uma medida da força dos eleitores habituais de Lula - movimentos sociais organizados, sindicatos e classe média - que provavelmente elegeram ou ajudaram a eleger os prefeitos do PT 2004. Se esse for o caso, o sinal negativo indica que esses eleitores habituais abandonaram Lula em 2006 (Zucco 2008). De todo o modo, trata-se de efeito incremental pequeno: em média a presença de prefeito do PT reduziu em $2,4(3,8)$ pontos percentuais a votação de Lula no primeiro turno (no segundo turno). O efeito do governador mostra-se substancialmente maior: aumento médio de 17,39 $(28,04)$ pontos percentuais no primeiro turno (segundo turno) (ver Tabela 5). Entretanto, ressalte-se que, na prática esse efeito teve pouca influência no resultado final, na medida em que em 2006 o PT somente governava estados com pequeno peso eleitoral (Acre, Piauí e Mato Grosso do Sul).

\footnotetext{
${ }^{15}$ Além disso, para $K=4$ as estimativas tornam-se quase todas não significativas.

${ }^{16} \mathrm{O}$ sinal é o contrário do encontrado em Zucco (2008).
} 
Tabela 3: ]

Resultados das Regressões - $1^{\circ}$ Turno, Variável Dependente $\ln [$ LULA20061T/(1-LULA20061T)]

\begin{tabular}{|c|c|c|c|}
\hline & $\begin{array}{l}\text { Modelo A1 } \\
(\mathrm{K}=1)\end{array}$ & $\begin{array}{l}\text { Modelo A2 } \\
(\mathrm{K}=2)\end{array}$ & $\begin{array}{l}\text { Modelo A3 } \\
(\mathrm{K}=3)\end{array}$ \\
\hline BOLSA & $\begin{array}{l}0,8713^{*} \\
(0,1212)\end{array}$ & $\begin{array}{r}1,6284^{*} \\
(0,2674)\end{array}$ & $\begin{array}{l}3,2808^{*} \\
(0,6646)\end{array}$ \\
\hline CRESC & $\begin{array}{c}0,1415^{* * *} \\
(0,0814)\end{array}$ & $\begin{array}{l}0,3081^{* *} \\
(0,1463)\end{array}$ & $\begin{array}{l}0,6709^{* *} \\
(0,2999)\end{array}$ \\
\hline URB & $\begin{array}{l}0,1583^{*} \\
(0,0420)\end{array}$ & $\begin{array}{r}0,2675^{*} \\
(0,0805)\end{array}$ & $\begin{array}{l}0,4709^{*} \\
(0,1703)\end{array}$ \\
\hline DENS & $\begin{array}{l}0,0000^{*} \\
(0,0000)\end{array}$ & $\begin{array}{r}0,0000^{*} \\
(0,0000)\end{array}$ & $\begin{array}{l}0,0001^{*} \\
(0,0000)\end{array}$ \\
\hline DIST & $\begin{array}{c}-0,0001^{*} \\
(0,0000)\end{array}$ & $\begin{array}{r}-0,0002^{*} \\
(0,0001)\end{array}$ & $\begin{array}{r}-0,0005^{*} \\
(0,0002)\end{array}$ \\
\hline LULA20021T & $\begin{array}{l}2,0238^{*} \\
(0,0624)\end{array}$ & $\begin{array}{r}3,8796^{*} \\
(0,2324)\end{array}$ & $\begin{array}{l}7,6562^{*} \\
(1,0508)\end{array}$ \\
\hline GOVPT & $\begin{array}{l}0,8288^{*} \\
(0,1264)\end{array}$ & $\begin{array}{r}1,4384^{*} \\
(0,2204)\end{array}$ & $\begin{array}{l}2,8146^{*} \\
(0,5550)\end{array}$ \\
\hline PREFPT & $\begin{array}{r}-0,0738^{*} \\
(0,0150)\end{array}$ & $\begin{array}{r}-0,1662^{*} \\
(0,0290)\end{array}$ & $\begin{array}{r}-0,3430^{*} \\
(0,0719)\end{array}$ \\
\hline PT004 & $\begin{array}{l}0,0699^{* *} \\
(0,0295)\end{array}$ & $\begin{array}{r}0,1589^{*} \\
(0,0554)\end{array}$ & $\begin{array}{l}0,2949^{*} \\
(0,1141)\end{array}$ \\
\hline RENDA & $\begin{array}{r}-0,0010^{*} \\
(0,0001)\end{array}$ & $\begin{array}{r}-0,0014^{*} \\
(0,0001)\end{array}$ & $\begin{array}{r}-0,0025^{*} \\
(0,0004)\end{array}$ \\
\hline GINI & $\begin{array}{r}-0,7534^{*} \\
(0,1254)\end{array}$ & $\begin{array}{r}-1,8040^{*} \\
(0,2475)\end{array}$ & $\begin{array}{r}-3,7744^{*} \\
(0,6748)\end{array}$ \\
\hline ANALF & $\begin{array}{l}0,8204^{*} \\
(0,1663)\end{array}$ & $\begin{array}{r}1,8433^{*} \\
(0,3562)\end{array}$ & $\begin{array}{l}3,4557^{*} \\
(0,8085)\end{array}$ \\
\hline MORT & $\begin{array}{l}0,5459 \\
(0,6322)\end{array}$ & $\begin{array}{c}1,3383 \\
(1,3550)\end{array}$ & $\begin{array}{l}2,1313 \\
(2,7191)\end{array}$ \\
\hline POBRES & $\begin{array}{c}0,0182 \\
(0,1575)\end{array}$ & $\begin{array}{c}0,2918 \\
(0,3189)\end{array}$ & $\begin{array}{l}0,8039 \\
(0,6452)\end{array}$ \\
\hline PENT & $\begin{array}{l}0,0047^{*} \\
(0,0012)\end{array}$ & $\begin{array}{r}0,0086^{*} \\
(0,0022)\end{array}$ & $\begin{array}{l}0,0159^{*} \\
(0,0048)\end{array}$ \\
\hline NBRANCO & $\begin{array}{l}1,2040^{*} \\
(0,0630)\end{array}$ & $\begin{array}{r}2,4435^{*} \\
(0,1782)\end{array}$ & $\begin{array}{l}5,1463^{*} \\
(0,7969)\end{array}$ \\
\hline TXLOCAL & $\begin{array}{l}0,5446^{*} \\
(0,1086)\end{array}$ & $\begin{array}{r}0,8561^{*} \\
(0,1898)\end{array}$ & $\begin{array}{l}1,4586^{*} \\
(0,3961)\end{array}$ \\
\hline PUBLICO & $\begin{array}{l}0,4470^{*} \\
(0,0857)\end{array}$ & $\begin{array}{r}0,9943^{*} \\
(0,1847)\end{array}$ & $\begin{array}{l}2,0268^{*} \\
(0,4704)\end{array}$ \\
\hline$\phi_{2}$ & - & $\begin{array}{r}-0,0408^{*} \\
(0,0017)\end{array}$ & $\begin{array}{r}-0,0513^{*} \\
(0,0042)\end{array}$ \\
\hline$\phi_{3}$ & - & - & $\begin{array}{l}0,0011^{*} \\
(0,0002)\end{array}$ \\
\hline Teste para Viés de Agregação & - & $71,97^{*}$ & $82,36^{*}$ \\
\hline Número de Observações & 3398 & 3398 & 3398 \\
\hline $\mathrm{R}^{2}$ & 0,8398 & 0,8431 & 0,8436 \\
\hline $\mathrm{R}^{2}$ Ajustado & 0,8377 & 0,8411 & 0,8415 \\
\hline Critério de Seleção de Akaike & 451,44 & 381,48 & 373,09 \\
\hline
\end{tabular}

Os símbolos *,** $\mathrm{e}^{* * *}$ indicam significância a 1\%,5\% e $10 \%$, respectivamente.

Omitiu-se o valor da constante e dos efeitos estaduais por economia de espaço.

Entre parênteses os desvios-padrão das estimativas, robustas à

heterocedasticidade da forma como definida na seção 3.2. O teste para viés de agregação reporta a estatística $\chi^{2}$ relativa à significância conjunta de $\phi_{2}, \ldots, \phi_{K}$ (mais detalhes ver seção 3.1). 
Tabela 4: ]

Resultados das Regressões - $2^{\circ}$ Turno, Variável Dependente $\ln [$ LULA20062T/(1-LULA20062T)]

\begin{tabular}{|c|c|c|c|}
\hline & $\begin{array}{l}\text { Modelo B1 } \\
(\mathrm{K}=1)\end{array}$ & $\begin{array}{l}\text { Modelo B2 } \\
(\mathrm{K}=2)\end{array}$ & $\begin{array}{l}\text { Modelo B3 } \\
(\mathrm{K}=3)\end{array}$ \\
\hline BOLSA & $\begin{array}{l}0,7606^{*} \\
(0,1205)\end{array}$ & $\begin{array}{r}1,3456^{*} \\
(0,2326)\end{array}$ & $\begin{array}{l}2,5214^{*} \\
(0,6288)\end{array}$ \\
\hline CRESC & $\begin{array}{l}0,3124^{*} \\
(0,0764)\end{array}$ & $\begin{array}{r}0,5218^{*} \\
(0,1303)\end{array}$ & $\begin{array}{l}1,0432^{*} \\
(0,3253)\end{array}$ \\
\hline URB & $\begin{array}{l}0,1910^{*} \\
(0,0399)\end{array}$ & $\begin{array}{r}0,2935^{*} \\
(0,0700)\end{array}$ & $\begin{array}{l}0,5402^{*} \\
(0,1693)\end{array}$ \\
\hline DENS & $\begin{array}{l}0,0000^{*} \\
(0,0000)\end{array}$ & $\begin{array}{r}0,0000^{*} \\
(0,0000)\end{array}$ & $\begin{array}{l}0,0001^{*} \\
(0,0000)\end{array}$ \\
\hline DIST & $\begin{array}{r}-0,0002^{*} \\
(0,0000)\end{array}$ & $\begin{array}{r}-0,0004^{*} \\
(0,0000)\end{array}$ & $\begin{array}{r}-0,0009^{*} \\
(0,0002)\end{array}$ \\
\hline LULA20022T & $\begin{array}{l}2,5165^{*} \\
(0,5773)\end{array}$ & $\begin{array}{r}4,3977^{*} \\
(0,2664)\end{array}$ & $\begin{array}{l}8,4817^{*} \\
(1,6855)\end{array}$ \\
\hline GOVPT & $\begin{array}{l}0,8300^{*} \\
(0,1126)\end{array}$ & $\begin{array}{r}1,3747^{*} \\
(0,1953)\end{array}$ & $\begin{array}{l}2,6411^{*} \\
(0,6821)\end{array}$ \\
\hline PREFPT & $\begin{array}{r}-0,0093^{*} \\
(0,0142)\end{array}$ & $\begin{array}{r}-0,1737^{*} \\
(0,0266)\end{array}$ & $\begin{array}{r}-0,3323^{*} \\
(0,0778)\end{array}$ \\
\hline PT2004 & $\begin{array}{l}0,0262 \\
(0,0280)\end{array}$ & $\begin{array}{r}0,0454 \\
(0,0479)\end{array}$ & $\begin{array}{c}0,0835 \\
(0,0932)\end{array}$ \\
\hline RENDA & $\begin{array}{c}-0,0007^{*} \\
(0,0001)\end{array}$ & $\begin{array}{r}-0,0009^{*} \\
(0,0001)\end{array}$ & $\begin{array}{r}-0,0017^{*} \\
(0,0004)\end{array}$ \\
\hline GINI & $\begin{array}{c}-0,7111^{*} \\
(0,1193)\end{array}$ & $\begin{array}{r}-1,4328^{*} \\
(0,2213)\end{array}$ & $\begin{array}{r}-2,8363^{*} \\
(0,6878)\end{array}$ \\
\hline ANALF & $\begin{array}{l}1,4776^{*} \\
(0,1673)\end{array}$ & $\begin{array}{r}2,6132^{*} \\
(0,3293)\end{array}$ & $\begin{array}{c}4,8197^{*} \\
(1,0868)\end{array}$ \\
\hline MORT & $\begin{array}{l}0,0832 \\
(0,6269)\end{array}$ & $\begin{array}{r}-0,7224 \\
(1,1809)\end{array}$ & $\begin{array}{r}-1,3468 \\
(2,2800)\end{array}$ \\
\hline POBRES & $\begin{array}{l}0,0295 \\
(0,1540)\end{array}$ & $\begin{array}{l}0,2185 \\
(0,2771)\end{array}$ & $\begin{array}{c}0,5304 \\
(0,5435)\end{array}$ \\
\hline PENT & $\begin{array}{l}0,0014 \\
(0,0011)\end{array}$ & $\begin{array}{l}0,0033^{* * *} \\
(0,0019)\end{array}$ & $\begin{array}{l}0,0061 \\
(0,0039)\end{array}$ \\
\hline NBRANCO & $\begin{array}{l}1,1542^{*} \\
(0,0608)\end{array}$ & $\begin{array}{r}2,1337^{*} \\
(0,1697)\end{array}$ & $\begin{array}{l}4,2940^{*} \\
(0,9345)\end{array}$ \\
\hline TXLOCAL & $\begin{array}{l}0,3713^{*} \\
(0,1011)\end{array}$ & $\begin{array}{r}0,5134^{*} \\
(0,1675)\end{array}$ & $\begin{array}{l}0,8656^{* *} \\
(0,3478)\end{array}$ \\
\hline PUBLICO & $\begin{array}{l}0,4665^{*} \\
(0,0832)\end{array}$ & $\begin{array}{r}0,8907^{*} \\
(0,1642)\end{array}$ & $\begin{array}{l}1,7401^{*} \\
(0,4776)\end{array}$ \\
\hline$\phi_{2}$ & - & $\begin{array}{r}-0,0327^{*} \\
(0,0012)\end{array}$ & $\begin{array}{r}-0,0463^{*} \\
(0,0039)\end{array}$ \\
\hline$\phi_{3}$ & - & - & $\begin{array}{l}0,0009^{*} \\
(0,0002)\end{array}$ \\
\hline Teste para Viés de Agregação & - & $52,66^{*}$ & $58,50^{*}$ \\
\hline Número de Observações & 3398 & 3398 & 3398 \\
\hline $\mathrm{R}^{2}$ & 0,8648 & 0,8668 & 0,8671 \\
\hline $\mathrm{R}^{2}$ Ajustado & 0,863 & 0,8651 & 0,8653 \\
\hline Critério de Seleção de Akaike & 40,86 & $-9,80$ & $-13,64$ \\
\hline
\end{tabular}

Os símbolos *,** $\mathrm{e}^{* * *}$ indicam significância a 1\%,5\% e $10 \%$, respectivamente.

Omitiu-se o valor da constante e dos efeitos estaduais por economia de espaço.

Entre parênteses os desvios-padrão das estimativas, robustas à

heterocedasticidade da forma como definida na seção 3.2. O teste para viés de agregação reporta a estatística $\chi^{2}$ relativa à significância conjunta de $\phi_{2}, \ldots, \phi_{K}$ (mais detalhes ver seção 3.1). 
Tabela 5: Efeitos Marginais e Elasticidades

\begin{tabular}{|c|c|c|c|c|}
\hline & \multicolumn{2}{|c|}{ Modelo A3 $(\mathrm{K}=3)$} & \multicolumn{2}{|c|}{ Modelo B3 $(\mathrm{K}=3)$} \\
\hline & \multicolumn{2}{|c|}{$1^{\circ}$ Turno } & \multicolumn{2}{|c|}{$2^{\circ}$ Turno } \\
\hline & Efeito Marginal & Elasticidade & Efeito Marginal & Elasticidade \\
\hline BOLSA & $\begin{array}{l}0,1930^{*} \\
(0,0067)\end{array}$ & $\begin{array}{l}0,1034^{*} \\
(0,0017)\end{array}$ & $\begin{array}{l}0,1621^{*} \\
(0,0052)\end{array}$ & $\begin{array}{l}0,0735^{*} \\
(0,0014)\end{array}$ \\
\hline CRESC & $\begin{array}{l}0,0395^{* *} \\
(0,0157)\end{array}$ & $\begin{array}{l}0,0010^{* *} \\
(0,0004)\end{array}$ & $\begin{array}{l}0,0671^{*} \\
(0,0159)\end{array}$ & $\begin{array}{l}0,0014^{*} \\
(0,0003)\end{array}$ \\
\hline URB & $\begin{array}{l}0,0277^{*} \\
(0,0001)\end{array}$ & $\begin{array}{l}0,0311^{*} \\
(0,0001)\end{array}$ & $\begin{array}{l}0,0347^{*} \\
(0,0001)\end{array}$ & $\begin{array}{l}0,0330^{*} \\
(0,0001)\end{array}$ \\
\hline DENS & $\begin{array}{l}0,0000^{*} \\
(0,0000)\end{array}$ & $\begin{array}{l}0,0008^{*} \\
(0,0000)\end{array}$ & $\begin{array}{l}0,0000^{*} \\
(0,0000)\end{array}$ & $\begin{array}{l}0,0007^{*} \\
(0,0000)\end{array}$ \\
\hline DIST & $\begin{array}{r}-0,0000^{*} \\
(0,0000)\end{array}$ & $\begin{array}{r}-0,0149^{*} \\
(0,0035)\end{array}$ & $\begin{array}{r}-0,0001^{*} \\
(0,0000)\end{array}$ & $\begin{array}{r}-0,0218^{*} \\
(0,0027)\end{array}$ \\
\hline LULA20021T & $\begin{array}{l}0,4503^{*} \\
(0,0373)\end{array}$ & $\begin{array}{l}0,3646^{*} \\
(0,0159)\end{array}$ & - & - \\
\hline LULA20022T & - & - & $\begin{array}{l}0,5452^{*} \\
(0,0509)\end{array}$ & $\begin{array}{l}0,4685^{*} \\
(0,0153)\end{array}$ \\
\hline GOVPT & $\begin{array}{l}0,1739^{*} \\
(0,0178)\end{array}$ & - & $\begin{array}{l}0,2804^{*} \\
(0,0195)\end{array}$ & - \\
\hline PREFPT & $\begin{array}{r}-0,0240^{*} \\
(0,0031)\end{array}$ & - & $\begin{array}{r}-0,0380^{*} \\
(0,0031)\end{array}$ & - \\
\hline PT2004 & $\begin{array}{l}0,0173^{*} \\
(0,0006)\end{array}$ & $\begin{array}{l}0,0117^{*} \\
(0,0043)\end{array}$ & $\begin{array}{l}0,0054 \\
(0,0059)\end{array}$ & $\begin{array}{l}0,0031 \\
(0,0034)\end{array}$ \\
\hline RENDA & $\begin{array}{r}-0,0001^{*} \\
(0,0000)\end{array}$ & $\begin{array}{r}-0,0488^{*} \\
(0,0058)\end{array}$ & $\begin{array}{c}-0,0001^{*} \\
(0,0000)\end{array}$ & $\begin{array}{c}-0,0305^{*} \\
(0,0046)\end{array}$ \\
\hline GINI & $\begin{array}{r}-0,2220^{*} \\
(0,0263)\end{array}$ & $\begin{array}{r}-0,2309^{*} \\
(0,0279)\end{array}$ & $\begin{array}{c}-0,1823^{*} \\
(0,0258)\end{array}$ & $\begin{array}{c}-0,1605^{*} \\
(0,0222)\end{array}$ \\
\hline ANALF & $\begin{array}{l}0,2032^{*} \\
(0,0004)\end{array}$ & $\begin{array}{l}0,0778^{*} \\
(0,0002)\end{array}$ & $\begin{array}{l}0,3098^{*} \\
(0,0004)\end{array}$ & $\begin{array}{l}0,1003^{*} \\
(0,0001)\end{array}$ \\
\hline MORT & $\begin{array}{l}0,1254^{*} \\
(0,0001)\end{array}$ & $\begin{array}{l}0,0098^{*} \\
(0,0000)\end{array}$ & $\begin{array}{r}-0,0866^{*} \\
(0,0001)\end{array}$ & $\begin{array}{c}-0,0057^{*} \\
(0,0000)\end{array}$ \\
\hline POBRES & $\begin{array}{c}0,0473 \\
(0,0345)\end{array}$ & $\begin{array}{c}0,0242 \\
(0,0189)\end{array}$ & $\begin{array}{l}0,0341 \\
(0,0340)\end{array}$ & $\begin{array}{l}0,0148 \\
(0,0147)\end{array}$ \\
\hline PENT & $\begin{array}{l}0,0009^{*} \\
(0,0002)\end{array}$ & $\begin{array}{l}0,0146^{*} \\
(0,0040)\end{array}$ & $\begin{array}{l}0,0004 \\
(0,0002)\end{array}$ & $\begin{array}{l}0,0052 \\
(0,0031)\end{array}$ \\
\hline NBRANCO & $\begin{array}{l}0,3027^{*} \\
(0,0001)\end{array}$ & $\begin{array}{l}0,2521^{*} \\
(0,0001)\end{array}$ & $\begin{array}{l}0,2760^{*} \\
(0,0001)\end{array}$ & $\begin{array}{l}0,1945^{*} \\
(0,0001)\end{array}$ \\
\hline TXLOCAL & $\begin{array}{l}0,0858^{*} \\
(0,0207)\end{array}$ & $\begin{array}{l}0,0085^{*} \\
(0,0022)\end{array}$ & $\begin{array}{l}0,0556^{*} \\
(0,0208)\end{array}$ & $\begin{array}{l}0,0047^{*} \\
(0,0017)\end{array}$ \\
\hline PUBLICO & $\begin{array}{l}0,1192^{*} \\
(0,0002)\end{array}$ & $\begin{array}{l}0,0574^{*} \\
(0,0001)\end{array}$ & $\begin{array}{l}0,1118^{*} \\
(0,0002)\end{array}$ & $\begin{array}{l}0,0456^{*} \\
(0,0001)\end{array}$ \\
\hline
\end{tabular}

Os símbolos *** $\mathrm{e}^{* * *}$ indicam significância a 1\%,5\% e $10 \%$, respectivamente Efeitos marginais e elasticidades calculados nas médias amostrais não ponderadas pela população dos municípios (ver Tabela 2). Para as variáveis binárias GOVPT e PREFPT o valor calculado se refere ao efeito incremental de uma mudança discreta (de zero para um). Os desvios-padrão foram calculados pelo método Delta. 
Nota-se também que, a despeito da melhora do desempenho eleitoral de Lula nas regiões menos desenvolvidas, tudo mais constante, o candidato do PT ainda obteve maior votação proporcional em regiões mais urbanizadas (URB), mais densamente povoadas (DENS), mais próximas das capitais (DIST) e menos desiguais (GINI). ${ }^{17} \mathrm{O}$ mesmo pode ser dito a respeito dos municípios menos dependentes de transferências do governo estadual e federal (TXLOCAL). ${ }^{18}$ Nesse sentido, os resultados indicariam que, a princípio, Lula foi relativamente menos votado nos chamados 'rincões'. Entretanto, os efeitos marginais com relação à renda per capita $(R E N D A)$, taxa de analfabetismo (ANALF), proporção de famílias pobres (POBRES) e do tamanho do setor público na economia (PUBLICO) indicam que tal conclusão é precipitada. Os resultados da Tabela 5 indicam que um incremento de $1 \%$ na renda per capita municipal gera uma redução de $0,0488 \%(0,0305 \%)$ na votação de Lula no primeiro turno (segundo turno) das eleições presidenciais de 2006. A mesma redução na taxa de analfabetismo (ou incremento na participação da administração pública no PIB municipal) gera aumentos de magnitude semelhantes na variável de interesse. No caso da proporção de famílias pobres o efeito não se mostrou estatisticamente significativo (ver Tabela 5).

\subsection{Bolsa Família ou Economia?}

Na prática, a diferença entre o impacto do programa Bolsa Família e do desempenho econômico nas eleições presidenciais é bem maior do que os efeitos marginais fazem supor. A média (sem ponderação) do crescimento do PIB per capita entre os municípios da amostra no período 2002-2006 é 1,4\% (ver Tabela 2). Nesse caso, o aumento de um ponto percentual implica quase dobrar o crescimento médio no período. Por sua vez, o alcance médio do programa Bolsa Família é de 28,9\% (ver Tabela 2). Em outras palavras, melhorar em um ponto percentual o desempenho econômico significa elevar em $70 \%$ a taxa de crescimento do PIB, enquanto o mesmo aumento no alcance do programa Bolsa Família implica incrementar em apenas 3,5\% o número de famílias beneficiadas. Não por acaso, tomando-se as elasticidades da Tabela 5, um incremento de $1 \%$ na variável CRESC eleva em somente $0,0010 \%(0,0014 \%)$ os votos no candidato do PT no primeiro turno (segundo turno). O mesmo aumento percentual em BOLSA resulta em elevação de 0,1033\% dos votos de Lula no primeiro turno e $0,0735 \%$ no segundo turno.

A diferença dos efeitos do programa Bolsa Família e do desempenho econômico também pode ser compreendida com a ajuda de exercícios contrafactuais. Nesse caso, como os resultados são similares para os dois turnos, o foco será mantido no segundo turno. ${ }^{19}$ Tome-se primeiro o programa de transferência de renda. Na Figura 3, cada ponto do painel (a) é o valor previsto da votação de Lula no segundo turno caso o programa Bolsa Família não existisse e se a taxa de crescimento no município fosse nula (calculados a partir do modelo B3 - ver Tabela 4). Esses valores são contrapostos à votação do candidato do PT nas eleições presidenciais de 2002. Além disso, é reportado (acima à esquerda) o resultado da regressão da votação de Lula em 2006 sem

\footnotetext{
${ }^{17} \mathrm{O}$ sinal da variável GINI se mostrou contrário ao encontrado em Shikida et al. (2009).

${ }^{18} \mathrm{O}$ aumento da taxa de mortalidade infantil (MORT) também deprime a votação de Lula, mas apenas no segundo turno. No primeiro turno o sinal encontrado foi positivo.

${ }^{19}$ A diferença principal é que no primeiro turno a relação entre a votação de Lula nas eleições de 2002 e 2006 é mais fraca do que no segundo turno.
} 
os efeitos do crescimento e do programa Bolsa Família (eixo das ordenadas) na votação de Lula em 2002 (eixo das abscissas), bem como a reta ajustada correspondente. O painel (b) reporta as mesmas informações do painel (a), mas considerando a cobertura observada do programa.

O que se percebe é que a distribuição de benefícios do programa Bolsa Família eleva o intercepto (de 0,3444 para 0,4330) e reduz a inclinação (de 0,4056 para 0,3246 ) da reta ajustada. Nota-se que, na média, o programa elevou a votação de Lula em todos os municípios, mas que o aumento foi maior justamente naqueles em que o seu desempenho foi relativamente pior em 2002.
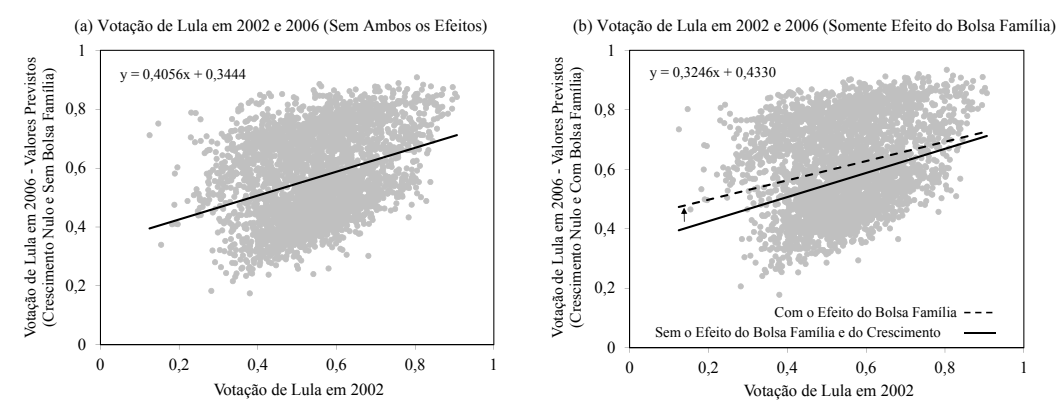

Valores calculados a partir do modelo B3 (ver Tabela 4).

Figura 3: Votação de Lula em 2006: Efeito do Programa Bolsa Família (2o Turno)

Exercício análogo foi feito para o desempenho da economia, medido pela taxa de crescimento do PIB per capita (ver Figura 4). No entanto, o efeito do desempenho da economia foi bastante modesto se comparado ao impacto do programa Bolsa Família, tanto que sequer é discernível a olho nu como no gráfico da Figura 3.
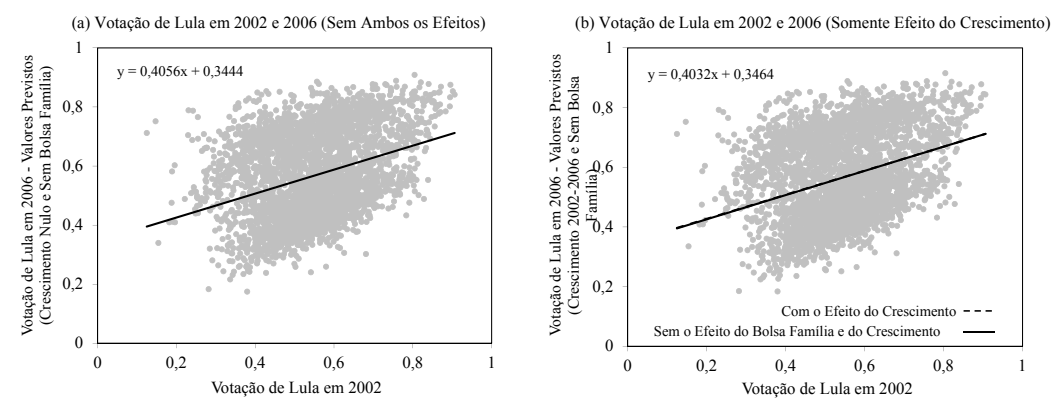

Valores calculados a partir do modelo B3 (ver Tabela 4).

Figura 4: Votação de Lula em 2006: Efeito do Crescimento do PIB Per Capita (2० Turno)

A Figura 5 e a Figura 6 ilustram a diferença entre os impactos do programa Bolsa Família e do desempenho econômico. No painel (a) da Figura 5 fica claro que o programa influenciou positivamente o desempenho eleitoral de Lula em 2006, e que esse efeito foi mais importante nos municípios em que tradicionalmente o seu desempenho era pior. A Tabela 6 e a Tabela 7 reforçam esse argumento. O efeito do programa Bolsa Família nos estados das regiões 
Norte e Nordeste foi superior ao impacto nos demais estados. Por exemplo, em Alagoas o programa aumentou em $9,45(7,64)$ pontos percentuais a votação de Lula no primeiro turno (segundo turno), enquanto no Rio de Janeiro e São Paulo o incremento foi de somente $1,51(0,98)$ e $1,92(1,65)$ ponto percentual, respectivamente.

O painel (b) da Figura 5 explora a ligação entre o desempenho de Lula nas eleições presidenciais de 2002 e o nível de desenvolvimento dos municípios. O efeito do programa Bolsa Família na votação de Lula foi superior nos municípios mais pobres.

Por sua vez, o painel (a) da Figura 6 indica que o efeito eleitoral do crescimento foi relativamente menos importante do que o impacto do programa Bolsa Família, sendo praticamente nulo na média dos municípios da amostra. Mais uma vez, a Tabela 6 e a Tabela 7 reforçam este argumento: tomando-se o Brasil com um todo, o efeito do programa Bolsa Família na votação de Lula em 2006 foi de $3,30(2,68)$ pontos percentuais no primeiro turno (segundo turno), o equivalente a pouco mais de 3,1 milhões $(2,5$ milhões) de votos. Trata-se de aproximadamente dezessete vezes $(3,30 \div 0,19)$ o efeito do crescimento no primeiro turno e mais do que oito vezes $(2,68 \div 0,31)$ no segundo turno. ${ }^{20}$ É um impacto modesto, principalmente quando se considera que em $2006 \mathrm{o}$ número de famílias atendidas pelo programa era aproximadamente onze milhões. Além disso, o painel (b) da Figura 6 mostra que a relação tênue entre o efeito eleitoral do desempenho da economia com a votação de Lula em 2002 se repete quando se considera a renda per capita dos municípios.
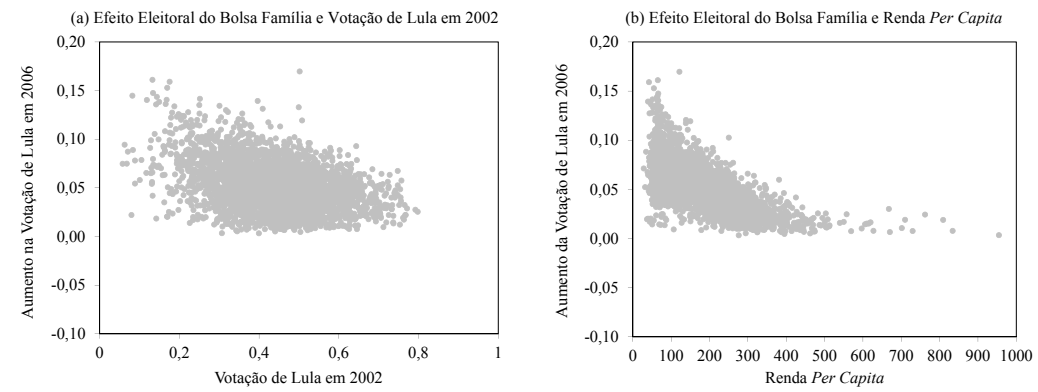

Figura 5: Efeito Eleitoral do Programa Bolsa Família (2 Turno)

\subsection{Nem Bolsa Família nem Economia: o que Mudou Afinal?}

Da seção 5.3 percebe-se que o desempenho da economia e o programa Bolsa Família, principalmente este último, tiveram impacto no resultado das eleições presidenciais de 2006. No entanto, fica claro que, sozinhos, não são capazes de explicar a mudança do padrão de votos de Lula entre 2002 e 2006. A Figura 7 ilustra esse argumento para o segundo turno (os resultados para o primeiro turno são similares). A linha pontilhada de $45^{\circ}$ indica a votação

\footnotetext{
${ }^{20}$ Novamente, a diferença entre os impactos do programa Bolsa Família e do crescimento da economia na votação de Lula no primeiro e no segundo turno está em linha com os resultados encontrados na Tabela 5. O efeito marginal da variável BOLSA é um pouco menor no segundo turno, enquanto o efeito marginal da variável CRESC é quase o dobro.
} 
Tabela 6: Votação de Lula: Valores Previstos por Estados - $1^{\circ}$ Turno (Modelo A3)

\begin{tabular}{|c|c|c|c|c|c|c|c|}
\hline & \multirow{3}{*}{ Observado $^{a}$} & \multirow{3}{*}{ Previsto } & Previsto & Previsto & Previsto & \multirow{2}{*}{$\begin{array}{l}\text { Efeito do } \\
\text { Bolsa } \\
\text { Família }\end{array}$} & \multirow{2}{*}{$\begin{array}{l}\text { Efeito do } \\
\text { Crescimento }\end{array}$} \\
\hline & & & $\begin{array}{l}\text { Sem Ambos } \\
\text { os Efeitos }\end{array}$ & $\begin{array}{l}\text { Somente Efeito } \\
\text { do Bolsa Família }\end{array}$ & $\begin{array}{l}\text { Somente Efeito } \\
\text { do Crescimento }\end{array}$ & & \\
\hline & & & {$[\mathrm{A}]$} & [B] & [C] & [B]-[A] & {$[\mathrm{C}]-[\mathrm{A}]$} \\
\hline $\mathrm{RO}$ & $46,30 \%$ & $46,60 \%$ & $41,60 \%$ & $46,40 \%$ & $41,80 \%$ & $4,82 \%$ & $0,20 \%$ \\
\hline $\mathrm{AC}$ & $42,00 \%$ & $42,60 \%$ & $35,40 \%$ & $42,30 \%$ & $35,70 \%$ & $6,88 \%$ & $0,35 \%$ \\
\hline $\mathrm{AM}$ & $77,40 \%$ & $77,10 \%$ & $74,80 \%$ & $77,10 \%$ & $74,80 \%$ & $2,30 \%$ & $0,01 \%$ \\
\hline RR & $25,70 \%$ & $26,10 \%$ & $19,00 \%$ & $25,60 \%$ & $19,50 \%$ & $6,64 \%$ & $0,49 \%$ \\
\hline $\mathrm{PA}$ & $50,20 \%$ & $50,10 \%$ & $45,00 \%$ & $50,00 \%$ & $45,20 \%$ & $4,97 \%$ & $0,15 \%$ \\
\hline $\mathrm{AP}$ & $52,70 \%$ & $52,60 \%$ & $49,80 \%$ & $52,40 \%$ & $50,00 \%$ & $2,65 \%$ & $0,16 \%$ \\
\hline TO & $58,70 \%$ & $59,10 \%$ & $53,50 \%$ & $58,60 \%$ & $54,00 \%$ & $5,14 \%$ & $0,56 \%$ \\
\hline MA & $75,20 \%$ & $74,70 \%$ & $69,20 \%$ & $74,40 \%$ & $69,60 \%$ & $5,14 \%$ & $0,35 \%$ \\
\hline PI & $66,60 \%$ & $66,10 \%$ & $59,80 \%$ & $65,90 \%$ & $60,00 \%$ & $6,13 \%$ & $0,27 \%$ \\
\hline $\mathrm{CE}$ & $70,40 \%$ & $70,10 \%$ & $65,00 \%$ & $69,90 \%$ & $65,10 \%$ & $4,97 \%$ & $0,18 \%$ \\
\hline RN & $56,50 \%$ & $56,00 \%$ & $50,20 \%$ & $55,80 \%$ & $50,40 \%$ & $5,65 \%$ & $0,23 \%$ \\
\hline $\mathrm{PB}$ & $66,50 \%$ & $66,20 \%$ & $60,40 \%$ & $66,10 \%$ & $60,50 \%$ & $5,70 \%$ & $0,13 \%$ \\
\hline $\mathrm{PE}$ & $70,30 \%$ & $69,90 \%$ & $65,50 \%$ & $69,90 \%$ & $65,50 \%$ & $4,43 \%$ & $0,01 \%$ \\
\hline $\mathrm{AL}$ & $44,30 \%$ & $43,80 \%$ & $34,20 \%$ & $43,60 \%$ & $34,30 \%$ & $9,45 \%$ & $0,15 \%$ \\
\hline $\mathrm{SE}$ & $45,30 \%$ & $45,40 \%$ & $38,60 \%$ & $45,20 \%$ & $38,80 \%$ & $6,60 \%$ & $0,26 \%$ \\
\hline BA & $67,20 \%$ & $66,90 \%$ & $62,00 \%$ & $66,80 \%$ & $62,20 \%$ & $4,74 \%$ & $0,15 \%$ \\
\hline MG & $51,00 \%$ & $51,10 \%$ & $47,30 \%$ & $51,00 \%$ & $47,40 \%$ & $3,71 \%$ & $0,12 \%$ \\
\hline ES & $51,60 \%$ & $51,70 \%$ & $47,70 \%$ & $51,40 \%$ & $48,00 \%$ & $3,72 \%$ & $0,29 \%$ \\
\hline RJ & $48,40 \%$ & $48,20 \%$ & $46,50 \%$ & $48,00 \%$ & $46,70 \%$ & $1,51 \%$ & $0,15 \%$ \\
\hline SP & $36,70 \%$ & $36,80 \%$ & $34,60 \%$ & $36,50 \%$ & $34,80 \%$ & $1,92 \%$ & $0,26 \%$ \\
\hline PR & $37,40 \%$ & $37,50 \%$ & $34,00 \%$ & $37,30 \%$ & $34,10 \%$ & $3,37 \%$ & $0,15 \%$ \\
\hline SC & $33,00 \%$ & $33,70 \%$ & $31,60 \%$ & $33,50 \%$ & $31,80 \%$ & $1,88 \%$ & $0,23 \%$ \\
\hline RS & $33,40 \%$ & $33,60 \%$ & $30,60 \%$ & $33,60 \%$ & $30,70 \%$ & $2,92 \%$ & $0,05 \%$ \\
\hline MS & $35,90 \%$ & $36,00 \%$ & $32,00 \%$ & $35,90 \%$ & $32,20 \%$ & $3,85 \%$ & $0,11 \%$ \\
\hline MT & $38,20 \%$ & $38,40 \%$ & $34,30 \%$ & $38,20 \%$ & $34,60 \%$ & $3,89 \%$ & $0,28 \%$ \\
\hline GO & $38,90 \%$ & $39,30 \%$ & $35,60 \%$ & $39,00 \%$ & $35,90 \%$ & $3,38 \%$ & $0,23 \%$ \\
\hline DF & $37,10 \%$ & $37,10 \%$ & $35,00 \%$ & $36,40 \%$ & $35,60 \%$ & $1,45 \%$ & $0,62 \%$ \\
\hline Brasil & $47,30 \%$ & $47,30 \%$ & $43,80 \%$ & $47,10 \%$ & $44,00 \%$ & $3,30 \%$ & $0,19 \%$ \\
\hline
\end{tabular}

${ }^{a}$ Os valores observados se referem somente aos 3398 municípios incluídos na amostra e, portanto, diferem dos valores observados para o universo de 5582 municípios. 
Tabela 7: Votação de Lula: Valores Previstos por Estados — 2º Turno (Modelo B3)

\begin{tabular}{|c|c|c|c|c|c|c|c|}
\hline & \multirow{3}{*}{ Observado $^{a}$} & \multirow{3}{*}{ Previsto } & Previsto & Previsto & Previsto & \multirow{2}{*}{$\begin{array}{l}\text { Efeito do } \\
\text { Bolsa } \\
\text { Família }\end{array}$} & \multirow{2}{*}{$\begin{array}{l}\text { Efeito do } \\
\text { Crescimento }\end{array}$} \\
\hline & & & $\begin{array}{l}\text { Sem Ambos } \\
\text { os Efeitos }\end{array}$ & $\begin{array}{l}\text { Somente Efeito } \\
\text { do Bolsa Família }\end{array}$ & $\begin{array}{l}\text { Somente Efeito } \\
\text { do Crescimento }\end{array}$ & & \\
\hline & & & {$[\mathrm{A}]$} & {$[\mathrm{B}]$} & {$[\mathrm{C}]$} & [B]-[A] & {$[\mathrm{C}]-[\mathrm{A}]$} \\
\hline $\mathrm{RO}$ & $56.80 \%$ & $56.70 \%$ & $52.30 \%$ & $56.40 \%$ & $52.70 \%$ & $4.05 \%$ & $0.34 \%$ \\
\hline $\mathrm{AC}$ & $52.00 \%$ & $52.20 \%$ & $45.70 \%$ & $51.60 \%$ & $46.30 \%$ & $5.95 \%$ & $0.60 \%$ \\
\hline $\mathrm{AM}$ & $86.90 \%$ & $86.70 \%$ & $85.10 \%$ & $86.60 \%$ & $85.10 \%$ & $1.56 \%$ & $0.02 \%$ \\
\hline $\mathrm{RR}$ & $38.20 \%$ & $38.40 \%$ & $31.20 \%$ & $37.40 \%$ & $32.10 \%$ & $6.26 \%$ & $0.97 \%$ \\
\hline $\mathrm{PA}$ & $59.60 \%$ & $59.50 \%$ & $55.00 \%$ & $59.20 \%$ & $55.30 \%$ & $4.21 \%$ & $0.24 \%$ \\
\hline $\mathrm{AP}$ & $69.40 \%$ & $69.40 \%$ & $67.20 \%$ & $69.10 \%$ & $67.40 \%$ & $1.91 \%$ & $0.23 \%$ \\
\hline $\mathrm{TO}$ & $70.20 \%$ & $69.80 \%$ & $64.70 \%$ & $69.00 \%$ & $65.60 \%$ & $4.29 \%$ & $0.92 \%$ \\
\hline MA & $84.70 \%$ & $84.00 \%$ & $79.70 \%$ & $83.50 \%$ & $80.20 \%$ & $3.88 \%$ & $0.53 \%$ \\
\hline PI & $77.00 \%$ & $76.40 \%$ & $71.00 \%$ & $76.00 \%$ & $71.50 \%$ & $5.01 \%$ & $0.43 \%$ \\
\hline $\mathrm{CE}$ & $81.90 \%$ & $81.50 \%$ & $77.50 \%$ & $81.20 \%$ & $77.80 \%$ & $3.71 \%$ & $0.27 \%$ \\
\hline $\mathrm{RN}$ & $67.10 \%$ & $66.50 \%$ & $61.40 \%$ & $66.20 \%$ & $61.80 \%$ & $4.76 \%$ & $0.37 \%$ \\
\hline $\mathrm{PB}$ & $76.20 \%$ & $75.80 \%$ & $70.80 \%$ & $75.60 \%$ & $71.00 \%$ & $4.77 \%$ & $0.21 \%$ \\
\hline $\mathrm{PE}$ & $78.10 \%$ & $77.60 \%$ & $73.80 \%$ & $77.60 \%$ & $73.80 \%$ & $3.76 \%$ & $0.02 \%$ \\
\hline $\mathrm{AL}$ & $59.40 \%$ & $58.70 \%$ & $50.80 \%$ & $58.50 \%$ & $51.10 \%$ & $7.64 \%$ & $0.25 \%$ \\
\hline $\mathrm{SE}$ & $58.60 \%$ & $58.40 \%$ & $52.60 \%$ & $58.00 \%$ & $53.00 \%$ & $5.43 \%$ & $0.42 \%$ \\
\hline BA & $79.50 \%$ & $79.00 \%$ & $75.20 \%$ & $78.80 \%$ & $75.40 \%$ & $3.62 \%$ & $0.22 \%$ \\
\hline MG & $65.60 \%$ & $65.40 \%$ & $62.40 \%$ & $65.30 \%$ & $62.50 \%$ & $2.90 \%$ & $0.18 \%$ \\
\hline ES & $64.30 \%$ & $64.30 \%$ & $60.90 \%$ & $63.80 \%$ & $61.30 \%$ & $2.99 \%$ & $0.47 \%$ \\
\hline RJ & $69.20 \%$ & $69.00 \%$ & $67.80 \%$ & $68.80 \%$ & $68.10 \%$ & $0.98 \%$ & $0.21 \%$ \\
\hline SP & $47.60 \%$ & $47.50 \%$ & $45.40 \%$ & $47.10 \%$ & $45.90 \%$ & $1.65 \%$ & $0.45 \%$ \\
\hline PR & $48.80 \%$ & $48.80 \%$ & $45.60 \%$ & $48.50 \%$ & $45.90 \%$ & $2.88 \%$ & $0.27 \%$ \\
\hline SC & $45.30 \%$ & $45.60 \%$ & $43.60 \%$ & $45.20 \%$ & $44.00 \%$ & $1.62 \%$ & $0.40 \%$ \\
\hline RS & $45.20 \%$ & $45.30 \%$ & $42.70 \%$ & $45.20 \%$ & $42.80 \%$ & $2.52 \%$ & $0.09 \%$ \\
\hline MS & $45.00 \%$ & $45.00 \%$ & $41.50 \%$ & $44.90 \%$ & $41.70 \%$ & $3.38 \%$ & $0.19 \%$ \\
\hline MT & $49.60 \%$ & $49.70 \%$ & $45.90 \%$ & $49.20 \%$ & $46.40 \%$ & $3.30 \%$ & $0.48 \%$ \\
\hline GO & $53.70 \%$ & $53.80 \%$ & $50.60 \%$ & $53.40 \%$ & $51.00 \%$ & $2.77 \%$ & $0.39 \%$ \\
\hline $\mathrm{DF}$ & $57.00 \%$ & $57.00 \%$ & $54.90 \%$ & $56.00 \%$ & $55.90 \%$ & $1.11 \%$ & $0.97 \%$ \\
\hline Brasil & $59.80 \%$ & $59.70 \%$ & $56.70 \%$ & $59.40 \%$ & $57.00 \%$ & $2.68 \%$ & $0.31 \%$ \\
\hline
\end{tabular}

${ }^{a}$ Os valores observados se referem somente aos 3398 municípios incluídos na amostra e, portanto, diferem dos valores observados para o universo de 5582 municípios. 

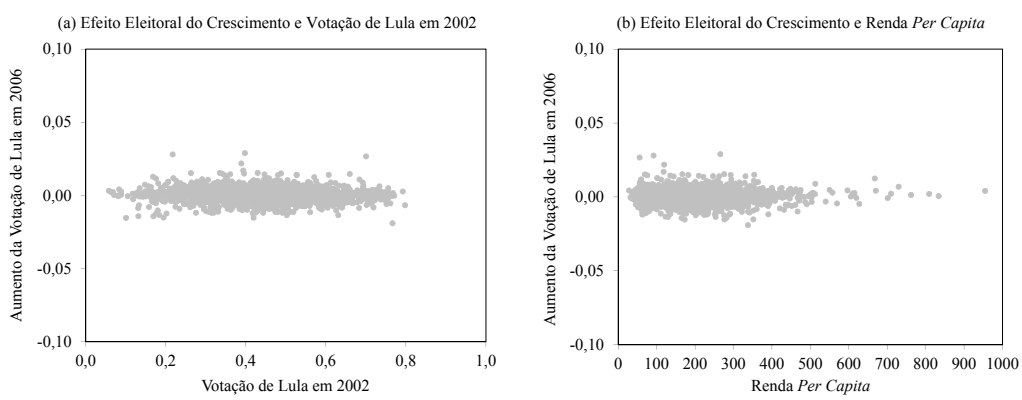

Figura 6: Efeito Eleitoral do Desempenho da Economia (2 Turno)

do candidato do PT caso este tivesse mantido o desempenho de 2002. A linha tracejada em negrito aponta a votação média prevista de Lula levando em consideração os efeitos do desempenho econômico e do programa de transferência de renda. Nota-se que ambos somente são capazes de explicar uma parte relativamente pequena da mudança: somente o deslocamento da linha em negrito para a linha tracejada em negrito. A diferença entre a linha de $45^{\circ}$ e a linha em negrito - indicada por setas - deve ser creditada a outras variáveis (incluídas ou não no modelo).

Uma possível causa seriam mudanças nas características dos municípios urbanização, densidade populacional e taxa de analfabetismo, por exemplo ou no ambiente político - prefeitos e governadores, por exemplo. Entretanto, ou essas variáveis apresentam pequeno efeito marginal na votação de Lula (ver Tabela 5), ou não costumam se alterar significativamente em um período de apenas quatro anos a ponto de explicar tamanha modificação do padrão da votação do candidato do PT.

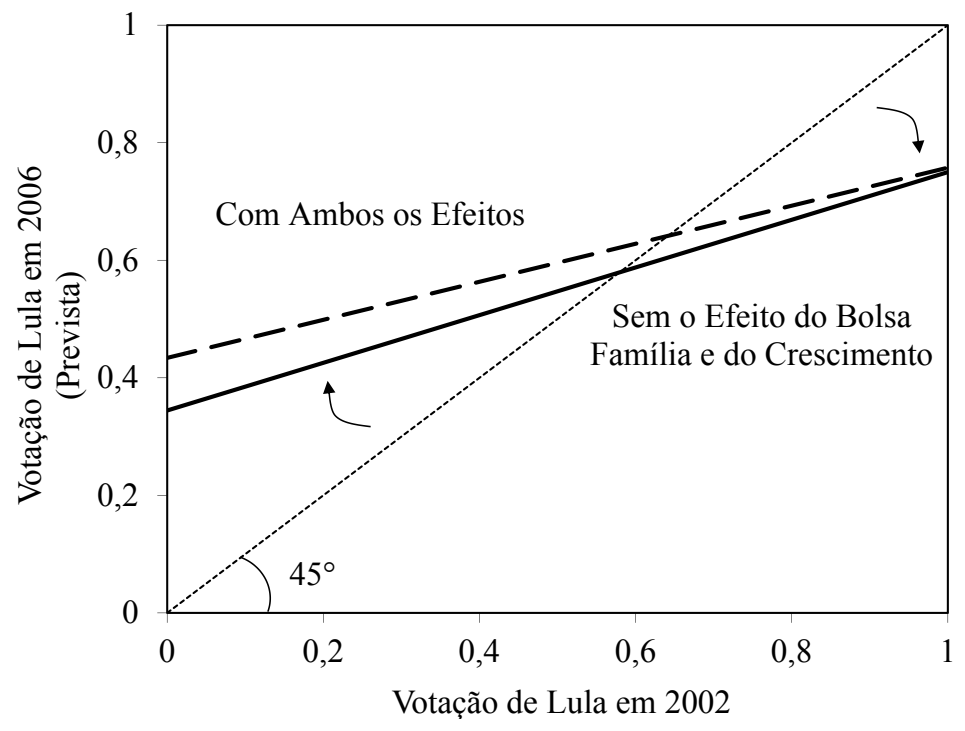

Figura 7: Mudança no Padrão Eleitoral de Lula: Resumo Esquemático (2º Turno) 
Nesse sentido, nos municípios mais desenvolvidos, a queda na votação de Lula poderia ser explicada pela percepção dos eleitores mais esclarecidos a respeito dos escândalos de corrupção que surgiram antes das eleições de 2006 (Hunter \& Power 2007). No entanto, esse fator não explicaria a melhora no desempenho eleitoral de Lula nos municípios menos desenvolvidos.

Desse modo, talvez a melhora da votação de Lula nos municípios em que tradicionalmente ele obtinha desempenho relativamente pior se deva ao fato de que, em 2006, pela primeira vez ele representava o governo estabelecido. Trata-se do argumento levantado em Zucco (2008) que, independentemente de quem é o candidato, os eleitores de municípios menos desenvolvidos, mais dependentes do Estado, seriam mais propensos a votar nas eleições para presidente a favor do governo. O contrário ocorreria nos municípios mais desenvolvidos. Esse argumento tenderia a ser reforçado pelo fato de que Lula não somente foi o candidato do governo, mas também concorreu à reeleição em 2006. Aliás, as análises de eleições e reeleições devem ser diferentes, pois nestas últimas o voto tende a ter vinculação com o desempenho anterior do candidato (Soares \& Terron 2008). Nesse sentido, a mudança no perfil de votos de Lula também pode estar relacionada com a percepção dos eleitores sobre o resultado de outras políticas de seu governo (que não o programa Bolsa Família e o crescimento econômico).

\subsection{O Problema de Identificação, Especificações Alternativas e Alguns Testes de Robustez}

Além do problema de identificação dos parâmetros do modelo de decisão individual a partir de regressões com dados agregados, que motivou o uso da metodologia proposta em Kelejian (1995), há outro problema de identificação que permeia a literatura que investiga o efeito eleitoral do programa Bolsa Família. Ao contrário de países como o México (ver De La O (2013) para detalhes), não houve programas piloto aleatórios, tampouco descontinuidades que possam ser exploradas na identificação da causalidade entre as variáveis de interesse. Além disso, a elegibilidade e a cobertura do programa são altamente correlacionadas com diversas variáveis socioeconômicas, o que dificulta ainda mais essa identificação (Zucco 2013).

Não há muito que fazer a esse respeito, salvo tentar descartar alguns problemas de identificação por meio de testes de robustez, quando possível. Nesse sentido, um possível problema pode estar associado à orientação ideológica dos eleitores. Se os beneficiários do programa Bolsa Família têm um viés ideológico esquerdista, parte do efeito da variável BOLSA na votação de Lula pode ser, na verdade, resultado desse viés. Desse modo, foram estimados modelos similares aos apresentados nas seções anteriores para outros candidatos à presidente nas eleições de 2006 (Geraldo Alckmin, Heloísa Helena e Cristovam Buarque). Os dois últimos são ideologicamente alinhados com a esquerda, como Lula. Caso se encontre algum efeito positivo da variável BOLSA na votação dos mesmos, seria uma indicação de que o viés esquerdista dos beneficiários contaminou a estimação do efeito do programa Bolsa Família.

Entretanto, os resultados da Tabela 8 mostra que para todos os candidatos o coeficiente da variável BOLSA se mostrou negativo. Embora esse resultado não permita descartar completamente a possibilidade de viés ideológico, tratase de um indício a esse respeito. 
Tabela 8: Impacto do Programa Bolsa Família na Votação de Outros Candidatos

\begin{tabular}{lc}
\hline & Coeficiente da Variável BOLSA \\
\hline Geraldo Alckmin (1 ${ }^{\circ}$ Turno) & $-1,2445^{*}$ \\
& $(0,2281)$ \\
Geraldo Alckmin (2 ${ }^{\circ}$ Turno) & $-1,0423^{*}$ \\
Cristovam Buarque (1 ${ }^{\circ}$ Turno) & $(0,1697)$ \\
Heloísa Helena (1 ${ }^{\circ}$ Turno) & $-0,1424^{* * *}$ \\
& $(0,0827)$ \\
\hline
\end{tabular}

Os símbolos * ${ }^{* *} \mathrm{e}^{* * *}$ indicam significância a $1 \%, 5 \%$ e $10 \%$, respectivamente
Entre parênteses os desvios-padrão das estimativas, robustas à
heterocedasticidade da forma como definida na seção 3.2 . Coeficientes
extraídos de modelos semelhantes aos estimados pata votação de Lula (ver
Tabela 3 e Tabela 4), mas com variáveis específicas do PT ( $L U L A 20021 T$,
LULA20022T, GOVPT, PREFPT, PT 2004) substituídas por variáveis
correspondentes ao partido de cada candidato. Todos os modelos estimados
com K = 3.

Outro problema de identificação está relacionado ao padrão espacial dos votos de Lula em 2006. Sendo assim, foram estimadas especificações nas quais a variável BOLSA interage com variáveis binárias regionais. Se no Nordeste o efeito for mais forte do que em regiões mais desenvolvidas, é possível que o discurso mais populista de Lula tenha tido papel relevante na mudança do seu padrão de votação. Nesse caso, é possível que o efeito estimado do programa Bolsa Família seja, ao menos em parte, resultado da identificação do públicoalvo nordestino com Lula. A Tabela 9 indica que para o segundo turno não parece haver tal viés. As interações não são conjuntamente significativas ao nível de confiança de $95 \%$. Também não é possível discernir, do ponto de vista estatístico, os coeficientes das interações que envolvem a variável binária do Nordeste e a do Sudeste. Entretanto, para o primeiro turno, as interações se mostram conjuntamente significantes e o coeficiente da interação que envolve a variável binária do Nordeste é claramente superior ao do Sudeste. Desse modo, os resultados do primeiro turno devem ser encarados com alguma reserva.

Por fim, convém retomar o resultado de que o efeito do programa Bolsa Família e do crescimento da economia é distinto em municípios com diferentes rendas per capita e votações de Lula em 2002. Sendo assim, foram estimados modelos similares aos modelos A3 e B3 (ver Tabela 3 e Tabela 4), mas adicionando-se seguintes interações: BOLSAxRENDA, BOLSAxLULA20021T (ou BOLSAxLULA20022T, para o segundo turno), CRESCXRENDA e CRESC$x$ LULA20021T (ou BOLSAxLULA20022T, para o segundo turno). A Tabela 10 apresenta os coeficientes das variáveis de interesse (BOLSA e CRESC) e das interações que as envolvem (os demais coeficientes não sofreram alterações importantes e, por isso, não foram apresentados). ${ }^{21}$

Novamente, os coeficientes estimados são de difícil interpretação. De todo modo, é possível perceber que, nos dois turnos, o efeito do programa Bolsa Família se reduz com o incremento da renda per capita. Por sua vez, a pro-

\footnotetext{
${ }^{21}$ Também foram estimados modelos com apenas algumas das interações. Como os resultados não se alteraram muito, somente as estimativas do modelo com todas as interações foram apresentadas.
} 
Tabela 9: Resultados de Especificações Alternativas - Interações com Efeitos Regionais

\begin{tabular}{|c|c|c|}
\hline & Modelo A4 $(\mathrm{K}=3)\left(1^{\circ}\right.$ Turno $)$ & Modelo B4 $(\mathrm{K}=3)\left(2^{\circ}\right.$ Turno $)$ \\
\hline Variável Dependente & $\ln [L U L A 20061 T /(1-L U L A 20061 T)]$ & $\ln [L U L A 20062 T /(1-L U L A 20062 T)]$ \\
\hline BOLSA & $\begin{array}{l}0,4814 \\
(1,0772)\end{array}$ & $\begin{array}{r}1,0035 \\
(0,8932)\end{array}$ \\
\hline CRESC & $\begin{array}{l}0,6975^{* *} \\
(0,3032)\end{array}$ & $\begin{array}{l}0,9798^{*} \\
(0,3086)\end{array}$ \\
\hline BOLSA $\times$ NORTE & $\begin{array}{r}1,5047 \\
(1,3795)\end{array}$ & $\begin{array}{l}0,2767 \\
(1,0622)\end{array}$ \\
\hline BOLSA $\times$ NORDESTE & $\begin{array}{l}4,5000^{*} \\
(1,2485)\end{array}$ & $\begin{array}{l}1,6753^{* * *} \\
(0,9123)\end{array}$ \\
\hline BOLSA $\times$ SUDESTE & $\begin{array}{r}1,6552 \\
(1,0932)\end{array}$ & $\begin{array}{l}1,7418^{* * *} \\
(0,9362)\end{array}$ \\
\hline $\mathrm{CRESC} \times \mathrm{SUL}$ & $\begin{array}{r}1,8461 \\
(1,1246)\end{array}$ & $\begin{array}{l}0,8704 \\
(0,9173)\end{array}$ \\
\hline $\begin{array}{l}\text { Coeficientes de Todas as } \\
\text { Interações São Nulos }\end{array}$ & $\begin{array}{l}29,90 \\
{[0,0000]}\end{array}$ & $\begin{array}{l}8,51 \\
{[0,0746]}\end{array}$ \\
\hline $\begin{array}{l}\text { Coeficiente da Interação } \\
\text { do Nordeste Igual ao do } \\
\text { Sudeste }\end{array}$ & $\begin{array}{l}17,82 \\
{[0,0000]}\end{array}$ & $\begin{array}{l}0,02 \\
{[0,8906]}\end{array}$ \\
\hline
\end{tabular}


Tabela 10: Resultados de Especificações Alternativas - Interações com LULA20021T (ou LULA20022T) e RENDA

\begin{tabular}{|c|c|c|}
\hline & Modelo A5 (K=3) (1 ${ }^{\circ}$ Turno $)$ & Modelo B5 $(\mathrm{K}=3)\left(2^{\circ}\right.$ Turno $)$ \\
\hline Variável dependente & $\ln [L U L A 20061 T /(1-L U L A 20061 T)]$ & $\ln [L U L A 20062 T /(1-L U L A 20062 T)]$ \\
\hline BOLSA & $\begin{array}{r}8,4816^{*} \\
(1,5041)\end{array}$ & $\begin{array}{c}10,6467^{*} \\
(2,6943)\end{array}$ \\
\hline CRESC & $\begin{array}{l}-2,1941^{* * *} \\
(1,1289)\end{array}$ & $\begin{array}{l}4,1215^{*} \\
(1,5258)\end{array}$ \\
\hline BOLSA $\times$ RENDA & $\begin{array}{r}-0,0123^{*} \\
(0,0034)\end{array}$ & $\begin{array}{c}-0,0025 \\
(0,0024)\end{array}$ \\
\hline BOLSA $\times$ LULA20021T & $\begin{array}{r}-7,4926^{*} \\
(1,8880)\end{array}$ & - \\
\hline BOLSA $\times$ LULA $20022 T$ & - & $\begin{array}{c}-13,6220^{*} \\
(3,5090)\end{array}$ \\
\hline CRESC $\times$ RENDA & $\begin{array}{r}0,0060^{*} \\
(0,0018)\end{array}$ & $\begin{array}{l}0,0055^{*} \\
(0,0119)\end{array}$ \\
\hline CRESC $\times$ LULA20021T & $\begin{array}{r}1,6264 \\
(2,3113)\end{array}$ & - \\
\hline CRESC $\times$ LULA20022T & - & $\begin{aligned}-8,2466^{*} \\
(2,6758)\end{aligned}$ \\
\hline
\end{tabular}

Os símbolos * ${ }^{* *} \mathrm{e}^{* * *}$ indicam significância a 1\%, 5\% e 10\%, respectivamente. Omitiu-se o valor dos demais coeficientes por economia de espaço. Entre parênteses os desvios-padrão das estimativas, robustas à heterocedasticidade da forma como definida na seção 3.2. O modelo A5 é semelhante ao modelo A3 (ver Tabela 3), com a adição das seguintes variáveis: BOLSA $\times$ NORTE, $B O L S A \times N O R D E S T E, B O L S A \times S U D E S T E$ e BOLSA $\times$ SUL. O modelo B5 é semelhante ao modelo B3 (ver Tabela 4), com a adição das seguintes variáveis: BOLSA $\times$ NORTE, BOLSA $\times$ NORDESTE, BOLSA $\times$ SUDESTE e BOLSA $\times S U L$. 
porção de votos em Lula nas eleições de 2002 aumenta (reduz) o impacto do crescimento econômico na votação de Lula em 2006 no primeiro (segundo) turno.

Entretanto, uma das vantagens da abordagem econométrica utilizada é que, embora não seja possível identificar os parâmetros do modelo de decisão individual, consegue-se inferir a importância relativa de cada variável na decisão do eleitor. Os parâmetros do modelo agregado permitem inferir algo sobre o comportamento individual. Mais especificamente, a razão entre cada um dos coeficientes do modelo de decisão individual - vetor $\vartheta$, ver equação 4 - e cada um dos coeficientes do modelo agregado - vetor $\lambda$, ver equação 10 - é a mesma $\left(1+b_{1}\right)$ (Heckelman 1997). Em outras palavras, tem-se que $\lambda=\left(1+b_{1}\right) \vartheta$.

Da equação 12 não é difícil perceber que, para o modelo agregado do primeiro turno, os efeitos marginais das variáveis BOLSA e CRESC na votação de Lula em $2006\left(\bar{D}_{s}\right)$ serão nulos quando:

$$
\begin{aligned}
& \Omega_{B O L S A} \equiv \lambda_{B O L S A}+\lambda_{1} R E N D A+\lambda_{2} L U L A 20021 T=0, \\
& \Omega_{C R E S C} \equiv \lambda_{C R E S C}+\lambda_{3} R E N D A+\lambda_{4} L U L A 20021 T=0,
\end{aligned}
$$

em que $\lambda_{B O L S A}$ é o coeficiente da variável BOLSA, $\lambda_{C R E S C}$ é o coeficiente da variável CRESC, $\lambda_{1}$ é o coeficiente da variável $B O L S A \times R E N D A, \lambda_{2}$ é o coeficiente da variável BOLSA $\times L U L A 20021 T, \lambda_{3}$ é o coeficiente da variável $C R E S C \times R E N D A$ e $\lambda_{4}$ é o coeficiente da variável CRESC $\times L U L A 20021 T$. Para o segundo turno, o resultado é análogo.

A título de ilustração, em um município em que a votação de Lula foi $100 \%$ em $2002(L U L A 20021 T=1)$ a renda per capita necessária para tornar nulo o efeito do programa Bolsa Família na votação de Lula em 2006 é:

$$
\overline{\operatorname{RENDA}}=-\frac{\lambda_{2}+\lambda_{B O L S A}}{\lambda_{1}}
$$

Como $\lambda=\left(1+b_{1}\right) \vartheta$, a condição que vale para o modelo agregado também vale para o modelo de decisão individual. Ou seja, para um eleitor que votou em Lula em 2002, a renda individual que torna nulo o efeito do recebimento do benefício do programa Bolsa Família na probabilidade de se votar nesse mesmo candidato em 2006 é exatamente a mesma calculada em 14:

$$
\begin{aligned}
\text { RENDA } & =\frac{\vartheta_{2}+\vartheta_{\text {BOLSA }}}{\vartheta_{1}} \\
& =-\frac{\left(1+b_{1}\right) \vartheta_{2}+\left(1+b_{1}\right) \vartheta_{B O L S A}}{\left(1+b_{1}\right) \vartheta_{1}} \\
& =-\frac{\lambda_{2}+\lambda_{B O L S A}}{\lambda_{1}} \\
& =\overline{R E N D A}
\end{aligned}
$$

em que $\vartheta_{\text {bolsa }}, \vartheta_{1}$ e $\vartheta_{2}$ são as contrapartidas individuais de $\lambda_{B O L S A}, \lambda_{1}$ e $\lambda_{2}$.

Nesse sentido, a Figura 8 apresenta um exercício bastante informativo para o primeiro turno das eleições. É calculado o valor de $\Omega_{B O L S A}$ para diferentes níveis de renda individual mensal. Também são discriminados os eleitores habituais de Lula $($ LULA20021T $=1)$ dos demais eleitores $(L U L A 20021 T=0)$. 
O mesmo é feito para o segundo turno na Figura 9. Note-se que, embora o exercício tenha sido feito para valores de renda até $\mathrm{R} \$ 2.000$ mensais, ele somente faz sentido para valores mais baixos, pois somente esses eleitores são elegíveis para participar do programa Bolsa Família. ${ }^{22}$ Desse modo, entre os eleitores habituais de outros candidatos que são elegíveis para participar do programa Bolsa Família, o efeito do recebimento do benefício é positivo. Por sua vez, tomando-se o mesmo grupo de renda, mas entre os eleitores habituais de Lula, e considerando-se intervalos de confiança calculados ao nível de significância de 5\%, o efeito é nulo (ou algo muito próximo disso).
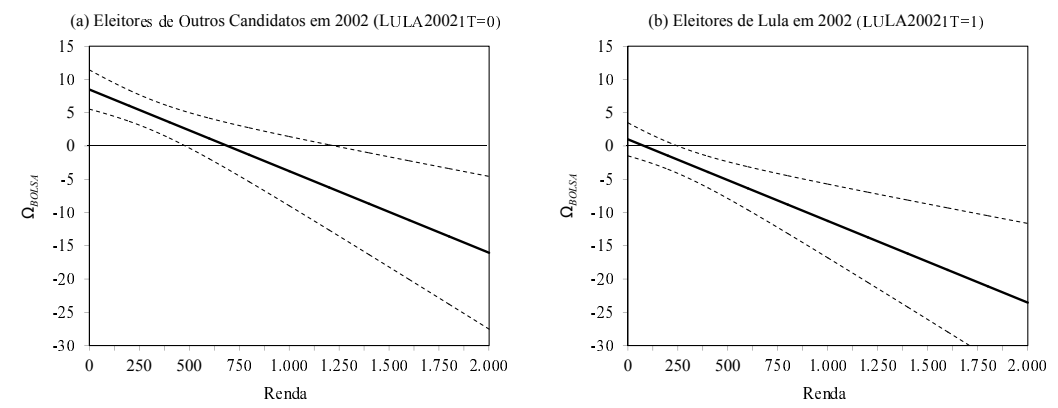

As linhas pontilhadas indicam o intervalo de confiança calculado a 95\%. Desvios-padrão calculados pelo método Delta.

Figura 8: $\Omega_{B O L S A}$ e Renda (1º Turno)
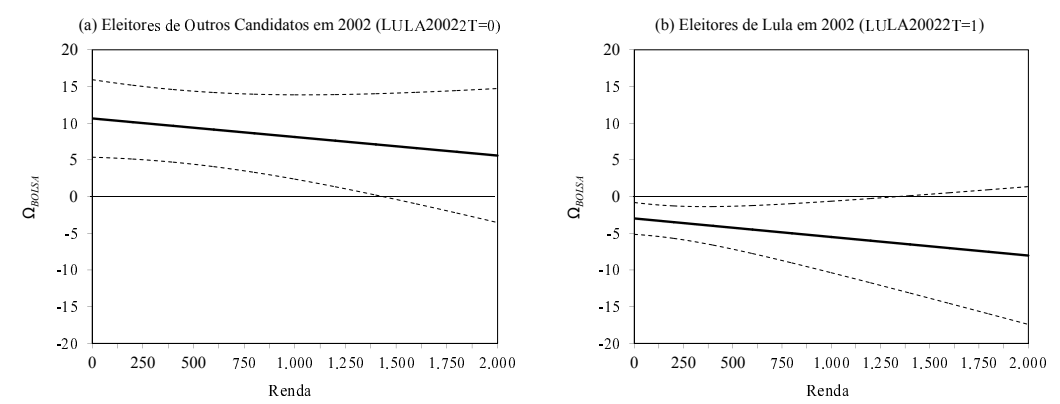

As linhas pontilhadas indicam o intervalo de confiança calculado a $95 \%$.

Desvios-padrão calculados pelo método Delta.

Figura 9: $\Omega_{B O L S A}$ e Renda (2० Turno)

A Figura 10 (Figura 11) repete o exercício da Figura 8 (Figura 9) para o

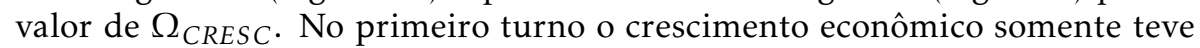
impacto positivo na votação de Lula em 2006 para eleitores mais ricos (a partir de R \$ 890 para eleitores habituais de outros candidatos e a partir de R\$ 520 para eleitores habituais de Lula, levando-se em consideração o intervalo de confiança de 95\%). No segundo turno o efeito foi sempre positivo para eleitores habituais de outros candidatos. Para eleitores habituais de Lula o efeito chega a ser negativo entre os eleitores muito pobres (renda abaixo de R $\$ 415$ ). Tais resultados parecem indicar que os eleitores mais pobres estão tão alijados

\footnotetext{
${ }^{22}$ De acordo com dados da PNAD de 2006, 75\% das pessoas beneficiadas pelo programa Bolsa Família tinham renda inferior R $\$ 575$ (a preços de 2000).
} 
dos ganhos advindos do crescimento econômico, que simplesmente não levaram essa variável em consideração quando decidiram seu voto nas eleições de 2006.
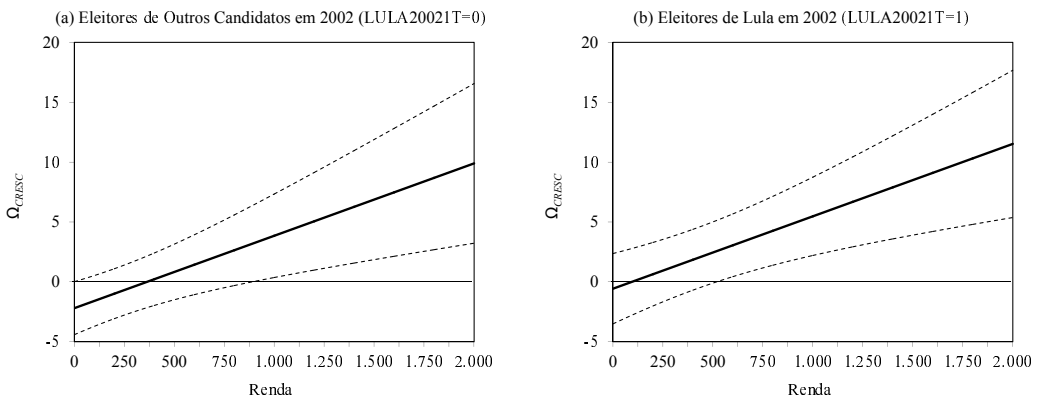

As linhas pontilhadas indicam o intervalo de confiança calculado a $95 \%$. Desvios-padrão calculados pelo método Delta.

Figura 10: $\Omega_{C R E S C}$ e Renda (1º Turno)
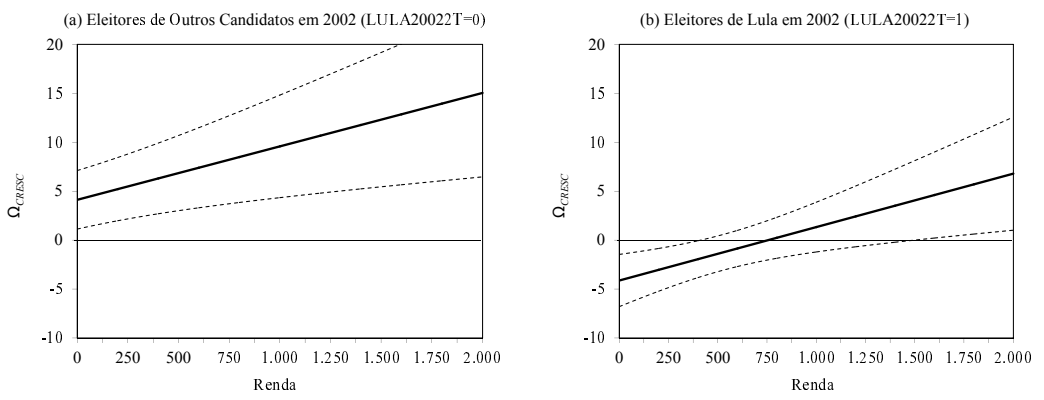

As linhas pontilhadas indicam o intervalo de confiança calculado a 95\%.

Desvios-padrão calculados pelo método Delta.

Figura 11: $\Omega_{C R E S C}$ e Renda (2० Turno)

\section{Considerações Finais}

O que explicaria a mudança no padrão de votação de Lula nas eleições presidenciais de 2006: desempenho da economia ou a massificação do programa Bolsa Família? Ao contrário de boa parte da literatura anterior, a resposta é: nenhum dos dois. O impacto do programa de transferência de renda se mostrou bastante superior ao do crescimento da economia, mas parece não ser a principal explicação para a migração significativa de votos em direção do candidato do PT nas regiões menos desenvolvidas do Brasil.

Nesse sentido, ganha bastante apelo a conjectura de que, independente do partido e do candidato, os eleitores de regiões menos desenvolvidas, mais dependentes do setor público, seriam mais propensos a votar no governo estabelecido (Zucco 2008). O mesmo pode ser dito com relação à hipótese de Hunter \& Power (2007) sobre os efeitos dos escândalos de corrupção na base eleitoral tradicional de Lula. No entanto, essas hipóteses são difíceis de serem empiricamente testadas. Uma possível abordagem é a utilização de dados de várias eleições. 
Ressalte-se também que a metodologia empregada nesse artigo (Kelejian 1995) tem a vantagem de lidar adequadamente com o problema de viés de agregação. Além disso, mesmo com dados agregados, essa metodologia permite alguma inferência sobre o comportamento individual dos eleitores. A esse respeito, entre eleitores habituais de Lula, o recebimento do programa Bolsa Família não aumenta a probabilidade de voto nesse candidato em 2006. Entre os eleitores habituais de outros candidatos, esse efeito é positivo. Por sua vez, um maior crescimento econômico somente se traduziu em mais votos para Lula em 2006 entre os eleitores mais ricos. Esses resultados parecem indicar que os eleitores mais pobres estão tão alijados dos ganhos advindos do crescimento econômico, que simplesmente não levaram essa variável em conta quando decidiram seu voto nas eleições de 2006.

Por fim, boa parte das variáveis explicativas foi incluída com valores do ano 2000. Trata-se de uma restrição imposta pela agregação das decisões individuais em nível municipal, cuja maioria das informações remete ao Censo Demográfico de 2000. Sendo assim, não é possível, por exemplo, um exercício contrafactual para a renda per capita (RENDA) como os realizados para as variáveis que medem o alcance do programa Bolsa Família e o crescimento econômico. Nesse caso, a única solução é o uso de dados agregados estaduais, mais sujeitos ao viés de agregação, porém com informações disponíveis para os anos de 2002 e 2006.

Nesse sentido, o uso de dados da Pesquisa Nacional de Amostras por Domicílio (PNAD) pode ser bastante promissor, inclusive porque o suplemento de 2006 permite identificar se determinado indivíduo pertence a uma família beneficiária do programa Bolsa Família (e o valor do benefício recebido), o que abriria caminho para o uso de modelos logit com coeficientes aleatórios (Nevo 2000). Esse tipo de modelagem permite considerar atributos individuais não observáveis e também a distribuição dos atributos individuais observáveis dos eleitores. ${ }^{23}$ Além disso, com as informações disponíveis na PNAD seria possível identificar melhor o efeito do desempenho da economia, na medida em que, além da taxa de crescimento do PIB, outras variáveis relacionadas ao ambiente econômico - renda do trabalho, desemprego e formalização, por exemplo - poderiam ser usadas. Nesse caso o efeito do crescimento pró-pobre na votação de Lula (Hunter \& Power 2007, Shikida et al. 2009) poderia ser mais bem medido. No entanto, tal estratégia somente será adotada em estudos subsequentes.

\section{Agradecimentos}

O autor agradece a César Zucco e Leonardo Monastério pelo compartilhamento das bases de dados usadas respectivamente em Zucco (2008) e Shikida et al. (2009). Agradecimento também a dois pareceristas anônimos, Adriana Hernandez-Perez, Samuel Pessôa, Régis Bonelli e diversos participantes de seminários no IBRE/FGV e na EPGE/FGV pelos comentários. Os erros remanescentes são de responsabilidade do autor e as opiniões expressas não refletem as posições da FGV ou do IBRE.

\footnotetext{
${ }^{23}$ Além disso, ao considerar a distribuição dos atributos individuais, este modelo contorna o problema de viés de agregação. Para uma aplicação deste modelo ao estudo de eleições ver Glasgow (2001).
} 


\section{Referências Bibliográficas}

Bohn, S. R. (2011), 'Social policy and vote in Brazil. Bolsa Familia and the Shifts in Lula's electoral base', Latin America Research Review 46(1), 54-79.

Brown, P. J. \& Payne, C. D. (1986), 'Aggregate data, ecological regression, and voting transitions', Journal of American Statistical Association 81(394), 452460 .

De La O, A. (2013), 'Do conditional cash transfers affect electoral behavior? evidence from a randomized experiment in Mexico', American Journal of Political Science 57(1), 1-14.

Freedman, D. A., Klein, S. P., Sacks, J., Smyth, C. A. \& Everett, C. G. (1991), 'Ecological regression and voting rights', Evaluation Review 15(6), 673-711.

Glasgow, G. (2001), 'Mixed logit models for multiparty elections', Political Analysis 9(2), 116-136.

Gorman, W. (1953), 'Community preference field', Econometrica 21(1), 6380 .

Heckelman, J. C. (1997), 'Determining who voted in historical elections: An aggregated logit approach', Social Science Research 26(2), 121-134.

Heckelman, J. C. (2000), 'Revisiting the relationship between secret ballots and turnout. a new test of two legal-institutional theories', American Politics Research 28(2), 194-215.

Heckelman, J. C. \& Sullivan, T. S. (2002), Testing for aggregation bias in a non-linear framework: Some Monte Carlo results, Mimeo, Winston-Salem, Edwardsville.

Hunter, W. \& Power, T. J. (2007), 'Rewarding Lula: Executive power, social policy, and the Brazilian elections of 2006', Latin American Politics and Society $49(1), 1-30$.

Kelejian, H. H. (1995), 'Aggregated heterogeneous dependent data and the logit model: A suggested approach', Economics Letters 47(3-4), 243-248.

Kieschnick, R. \& McCullough, B. D. (2003), 'Regression analysis of variates observed on $(0,1)$ : percentages, proportions and fractions', Statistical Modelling 3(3), 193-213.

King, G. (1997), A Solution to the Ecological Inference Problem: Reconstructing Individual Behavior from Aggregated Data, Princeton University Press, Princeton.

Labonne, J. (2013), 'The local electoral impacts of conditional cash transfers: Evidence from a field experiment', Journal of Development Economics 104, 7388 .

Licio, E. C., Rennó, L. R. \& Castro, H. C. O. (2009), 'Bolsa Família e o voto na eleição presidencial de 2006: em busca do elo perdido', Opinião Pública 15(1), 31-54. 
Maddala, G. S. (1983), Limited-Dependent and Qualitative Variables in Econometrics, Cambridge University Press, Cambridge.

Marques, R. M., Leite, M. G., Mendes, A. \& Ferreira, M. R. J. (2009), 'Discutindo o papel do programa Bolsa Família na decisão das eleições presidenciais brasileiras de 2006', Revista de Economia Política 29(1), 114-132.

Nevo, A. (2000), 'A practitioner's guide to estimation of random-coefficients logit models of demand', Journal of Economics \& Management Strategy 9(4), 513-548.

Nicolau, J. \& Peixoto, V. (2007), 'Uma disputa em três tempos: Uma análise das bases municipais das eleições presidenciais de 2006', Anais do XXXI Encontro Nacional da ANPOCS.

Shikida, C. D., Monasterio, L. M., Araujo Jr, A. F., Carraro, A. \& Damé, O. M. (2009), "It is the economy, companheiro!": an empirical analysis of Lula's re-election based on municipal data', Economics Bulletin 29(2), 977-992.

Soares, G. A. D. \& Terron, S. L. (2008), 'Dois Lulas: a geografia eleitoral da reeleição (explorando conceitos, métodos e técnicas de análise geoespacial)', Opinião Pública 14(2), 269-301.

Souza, T. C. \& Cribari Neto, F. (2013), 'Uma estimativa do impacto eleitoral do programa Bolsa-Família', Revista Brasileira de Biometria 31(1), 79-103.

Stoker, T. M. (1993), 'Empirical approaches to the problem of aggregation over individuals', Journal of Economic Literature 31(4), 1827-1874.

Train, K. E. (2003), Discrete Choice Methods with Simulation, Cambridge University Press, Cambridge.

Zucco, C. (2008), 'The president's 'new' constituency: Lula and the pragmatic vote in Brazil's 2006 presidential elections', Journal of Latin American Studies 40(1), 29-39.

Zucco, C. (2013), 'When payouts pay off: Conditional cash transfers and voting behavior in Brazil 2002-10', American Journal of Political Science 57(4), 810-822.

\section{Apêndice A Efeitos marginais, elasticidadese viés de agregação}

Na seção 5.1 foi mencionado que a incorporação da correção para o viés de agregação gerava diferenças não desprezíveis nas estimativas de efeitos marginais e de elasticidades. Nesse sentido, a Tabela A.1 ilustra essa afirmação para as duas principais variáveis explicativas utilizadas (BOLSA e CRESC).

Para o primeiro turno, comparando-se os modelos A1 e A3, nota-se que o efeito marginal da variável BOLSA (CRESC) é aproximadamente 11,3\% menor (11,7\% maior) quando se controla o viés de agregação. Analogamente, para o segundo turno (modelos B1 e B3), o efeito marginal da variável BOLSA (CRESC) é aproximadamente $9,1 \%$ menor (11,0\% menor). Resultados similares são encontrados para as elasticidades. A interpretação desses resultados é bastante difícil, na medida em que a magnitude e a direção do viés de agregação dependem da distribuição das variáveis explicativas entre os eleitores (ver seção 3.1). 
Tabela A.1: Efeitos Marginais e Elasticidades — Comparação entre Modelos

\begin{tabular}{llcccccc}
\hline & \multicolumn{3}{c}{$1^{\circ}$ Turno } & \multicolumn{3}{c}{$2^{\circ}$ Turno } \\
\hline \multirow{3}{*}{ BOLSA } & \multicolumn{3}{c}{ Modelo A1 Modelo A2 Modelo A3 Modelo B1 Modelo B2 Modelo B3 } \\
\cline { 2 - 8 } & Efeito & $0,2176^{*}$ & $0,2094^{* *}$ & $0,1930^{*}$ & $0,1783^{*}$ & $0,1763^{*}$ & $0,1621^{*}$ \\
& Marginal & $(0,0059)$ & $(0,0852)$ & $(0,0067)$ & $(0,0049)$ & $(0,0060)$ & $(0,0052)$ \\
& Elasticidade & $0,1217^{*}$ & $0,1130^{*}$ & $0,1034^{*}$ & $0,0826^{*}$ & $0,0800^{*}$ & $0,0735^{*}$ \\
& & $(0,0021)$ & $(0,0022)$ & $(0,0017)$ & $(0,0015)$ & $(0,0014)$ & $(0,0014)$ \\
CRESC & Efeito & $0,0353^{* * *}$ & $0,0396^{* *}$ & $0,0395^{* *}$ & $0,0732^{*}$ & $0,0684^{*}$ & $0,0671^{*}$ \\
& Marginal & $(0,0191)$ & $(0,0177)$ & $(0,0157)$ & $(0,0179)$ & $(0,0168)$ & $(0,0159)$ \\
& Elasticidade & $0,0009^{* * *}$ & $0,0010^{* *}$ & $0,0010^{* *}$ & $0,0016^{*}$ & $0,0015^{*}$ & $0,0014^{*}$ \\
& & $(0,0005)$ & $(0,0005)$ & $(0,0004)$ & $(0,0004)$ & $(0,0004)$ & $(0,0003)$ \\
\hline
\end{tabular}

Os símbolos *,** e ${ }^{* * *}$ indicam significância a $1 \%, 5 \%$ e $10 \%$, respectivamente Efeitos marginais e elasticidades calculados nas médias amostrais não ponderadas pela população dos municípios (ver Tabela 2). Os desvios-padrão foram calculados pelo método Delta. 